\title{
Structural and Femtosecond Third-Order Nonlinear Optical Properties of Sodium Borate Oxide Glasses: Effect of Antimony
}

\author{
Gangareddy Jagannath, ${ }^{\dagger, \#}$ Bheemaiah Eraiah, ${ }^{* \dagger}$ Anuraag Gaddam, ${ }^{\ddagger}, \#$ Hugo Fernandes, \\ Daniela Brazete, ${ }^{\ddagger}$ K. Jayanthi, ${ }^{\S \odot}$ Katturi Naga Krishnakanth, "Soma Venugopal Rao," \\ José M. F. Ferreira, ${ }^{*},+\infty$ K. Annapurna, ${ }^{\perp}$ and Amarnath R. Allu*, ${ }^{*} \odot$ \\ ${ }^{\dagger}$ Department of Physics, Bangalore University, 560056 Bengaluru, Karnataka, India \\ ${ }^{\ddagger}$ Department of Materials and Ceramic Engineering, CICECO, University of Aveiro, 3810-193 Aveiro, Portugal \\ ${ }^{\S}$ Department of Inorganic and Physical Chemistry, Indian Institute of Science, 560012 Bengaluru, Karnataka, India \\ "Advanced Centre of Research in High Energy Materials (ACRHEM), University of Hyderabad, 500046 Hyderabad, Telangana, \\ India \\ ${ }^{\perp}$ Glass Division, CSIR-Central Glass and Ceramic Research Institute, 700032 Kolkata, India
}

\begin{abstract}
Structural and optical properties of antimony-containing sodium borate glasses were studied and their ultrafast third-order nonlinear optical (NLO) properties have been evaluated using Z-scan measurements with femtosecond (fs) pulses $(\sim 150 \mathrm{fs}, 80 \mathrm{MHz})$ at 750,800 , and $880 \mathrm{~nm}$ wavelengths. Glasses in the $(\mathrm{mol} \%) 20 \mathrm{Na}_{2} \mathrm{O}-(80-x) \mathrm{B}_{2} \mathrm{O}_{3}-x \mathrm{Sb}_{2} \mathrm{O}_{3}$ (where $x=0,10,20$, and 30) system have been fabricated via melt quench technique. The structural modifications were analyzed using the Raman and magic angle spinning (MAS)-nuclear magnetic resonance (NMR) $\left({ }^{11} \mathrm{~B}\right.$ MAS-NMR and ${ }^{23} \mathrm{Na}$ MAS-NMR) techniques. The optical absorption spectra revealed that the absorption edge was red-shifted, suggesting the decrease in band gap energy with increase of antimony content in the glasses. Raman scattering results revealed that the boroxol rings are depressed with the incorporation of $\mathrm{Sb}_{2} \mathrm{O}_{3}$ for replacing $\mathrm{B}_{2} \mathrm{O}_{3} \cdot{ }^{11} \mathrm{~B}$ MAS-

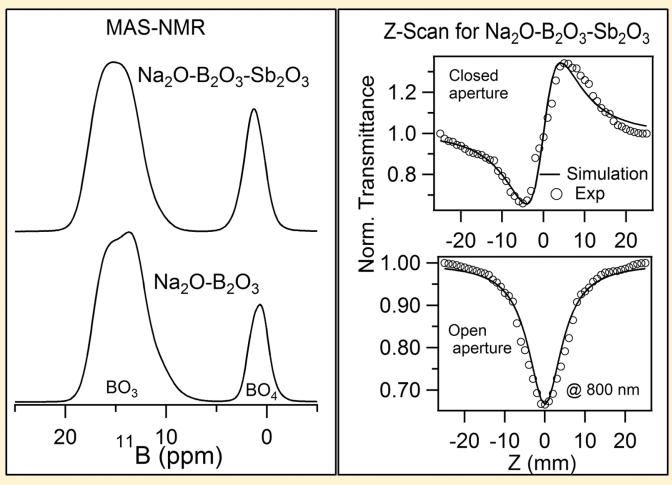
NMR results showed a progressive increase of $\mathrm{B}^{4}$ units at the expense of $\mathrm{B}^{3}$ units. The Raman and ${ }^{11} \mathrm{~B}$ MAS-NMR results support the formation of $\mathrm{Sb}^{5+}$ ions due to oxidation of $\mathrm{Sb}^{3+}$ that played the role of charge compensation. ${ }^{23} \mathrm{Na} \mathrm{MAS}-\mathrm{NMR}$ spectra revealed a decreasing trend in the average of bond lengths of $\mathrm{Na}-\mathrm{O}$ with increasing $\mathrm{Sb}_{2} \mathrm{O}_{3}$ contents. This suggested that sodium changed its role from charge compensator to modifier cation. The antimony-containing glasses demonstrated a reverse saturable absorption in open-aperture $Z$-scan mode due to two-photon absorption, while closed-aperture $Z$-scan signatures depicted positive nonlinear refraction due to self-focusing effect. The NLO coefficients were found to increase with $\mathrm{Sb}_{2} \mathrm{O}_{3}$ due to the increased nonbridging oxygens and also due to the hyperpolarizability of $\mathrm{Sb}^{3+}$ and $\mathrm{Sb}^{5+}$ ions. The observed $\mathrm{NLO}$ data clearly suggest that the investigated glasses are beneficial for optical limiting applications.
\end{abstract}

\section{INTRODUCTION}

Glass materials over the years have drawn a special consideration due to their wide and ever-growing applications in lasers, optical fiber amplifiers, flat-panel displays, optical limiting and switching devices, optoelectronic and memory devices, solar cells, and light-emitting diodes, and in the biomedical field. ${ }^{1-3}$ In the recent past, great attention has been paid to these materials for the development of optical devices and photonic components because of the ease of their fabrication and shaping. ${ }^{1}$ Additionally, the vitreous materials possess many unique properties such as high transparency and high optical damage threshold. Several researchers have been working extensively on inorganic glasses to achieve strong nonlinear coefficients, which are essential parameters for the utilization of material in nonlinear optical (NLO) devices. ${ }^{4,5}$ Among several types of glasses investigated, borate glasses have received huge attention owing to their low melting and glass- transition $\left(T_{\mathrm{g}}\right)$ temperatures, excellent physical-chemical properties, large coefficient of thermal expansion, and excellent optical properties. ${ }^{6}$ To satisfy the various demands in technological applications, optimization of the chemical composition and knowledge on the role of each cation in the glass material is essential. Furthermore, understanding the correlation between the optical properties and structural characteristics of glasses is fundamental for the development of glass materials for NLO applications. The development of anionic group theory ${ }^{7}$ has elucidated the structure-property relationship for NLO effects in inorganic materials based on perturbation theory for NLO susceptibilities of materials. According to the theory, the susceptibilities depend mainly on

Received: September 28, 2018

Revised: January 18, 2019

Published: February 11, 2019 
the boron-oxygen anionic group and their arrangement in space. Based on these considerations, among various existing $\left(\mathrm{B}_{x} \mathrm{O}_{y}\right)^{z-}$ borate groups, $\left(\mathrm{BO}_{3}\right)^{3-},\left(\mathrm{BO}_{4}\right)^{5-},\left(\mathrm{B}_{2} \mathrm{O}_{5}\right)^{4-}$, $\left(\mathrm{B}_{2} \mathrm{O}_{7}\right)^{8-},\left(\mathrm{B}_{3} \mathrm{O}_{6}\right)^{3-},\left(\mathrm{B}_{3} \mathrm{O}_{7}\right)^{5-},\left(\mathrm{B}_{3} \mathrm{O}_{8}\right)^{7-},\left(\mathrm{B}_{3} \mathrm{O}_{9}\right)^{9-}$, $\left(\mathrm{B}_{4} \mathrm{O}_{9}\right)^{6-}$, and $\left(\mathrm{B}_{5} \mathrm{O}_{10}\right)^{5-}$ are of practical interest for designing new NLO devices. ${ }^{78}$ It has been further reported that planar group with conjugated $\pi$-orbitals, such as $\left(\mathrm{BO}_{3}\right)^{3-}$ and $\left(\mathrm{B}_{3} \mathrm{O}_{6}\right)^{3-}$, are favorable for large susceptibilities than the nonplanar tetrahedral $\left(\mathrm{BO}_{4}\right)^{5-}$ anionic groups with no conjugated $\pi$-orbital. In supporting this, the high-performance NLO properties from borate materials have been achieved due to the presence of isolated $\left(\mathrm{BO}_{3}\right)^{3-}$ groups. ${ }^{9}$ Xue et al. ${ }^{10}$ attempted to understand the effect of chemical bond on the NLO properties and postulated that due to highly localized electrons, $\left(\mathrm{BO}_{3}\right)^{3-}$ groups exhibit larger NLO coefficients compared to the $\left(\mathrm{BO}_{4}\right)^{5-}$ groups, which in general contain less localized electrons. To shed further light on this issue, a thorough and in-depth structural investigation is essential and would lead to the understanding of the local environment and spatial distribution of the network formers in glasses. Therefore, one needs to ascertain and evaluate the different coordination polyhedra present, as well as their corresponding linkages with each other.

Owing to their hyperpolarizabilities and the ability to create nonbridging oxygens (NBOs), the incorporation of heavymetal oxides (HMOs) such as $\mathrm{Bi}_{2} \mathrm{O}_{3}, \mathrm{PbO}, \mathrm{TeO}_{2}, \mathrm{GeO}_{2}$, $\mathrm{GaO}_{2}, \mathrm{WO}_{3}, \mathrm{Nb}_{2} \mathrm{O}_{5}, \mathrm{Sb}_{2} \mathrm{O}_{3}$, etc. significantly alters the structure and properties of borate glasses. ${ }^{11-17}$ They enhance the NLO properties of the borate glass to several orders of magnitude due to the greater polarizability of heavy-metal cations. ${ }^{18,19}$ Shanmugavelu et al. ${ }^{4}$ elucidated that the enhancement in third-order nonlinearity is due to the increase in $\mathrm{BiO}_{6}$ groups containing $\mathrm{NBO}$ s with the increase of $\mathrm{Bi}_{2} \mathrm{O}_{3}$ concentration in bismuth zinc borate glasses. Rao et al. ${ }^{18,19}$ further demonstrated the effect of $\mathrm{Bi}_{2} \mathrm{O}_{3}$ on the NLO properties of borate glasses and obtained larger nonlinear effects due to the presence of hyperpolarizable anionic $\left[\mathrm{BiO}_{4}\right]^{5-}$ groups in borate glasses. It is interesting to note that utilization of composition-structure-property interrelationship for different $\mathrm{HMOs}^{11-16}$ in borate glasses is well documented. On the other hand, few reports ${ }^{17,20-24}$ are available on utilizing the composition-structure-property relationship for $\mathrm{Sb}_{2} \mathrm{O}_{3}$-containing borate glasses to understand the observed NLO properties. It is well known that antimony(III) oxide, $\mathrm{Sb}_{2} \mathrm{O}_{3}$, is a good low-phonon and highrefractive-index HMO glass former. ${ }^{25}$ Owing to the high polarizability and the presence of a stereochemically active lone pair of electrons, antimony-containing borate glasses are also considered as promising NLO materials. ${ }^{26}$ Terashima et al. ${ }^{17}$ studied the $\mathrm{Sb}_{2} \mathrm{O}_{3}-\mathrm{B}_{2} \mathrm{O}_{3}$ glasses and reported that the thirdorder nonlinear optical susceptibility $\left[\chi^{(3)}\right]$ of binary borate glasses is enhanced with increasing $\mathrm{Sb}_{2} \mathrm{O}_{3}$ content. FalcãoFilho et al. ${ }^{27}$ demonstrated that the antimony orthophosphate glasses possess excellent nonlinear refractive index at $800 \mathrm{~nm}$. Very recently, it has been observed that sodium borate glasses with a small amount $(2 \mathrm{~mol} \%)$ of antimony resulted in a small two-photon absorption (2PA) at $800 \mathrm{~nm}$ in femtosecond (fs) regime. $^{28}$ It is to be noted that the extent and ability of accepting high concentration of $\mathrm{Sb}_{2} \mathrm{O}_{3}$ depends strongly on the type of glass network former. ${ }^{29}$ Som et al. ${ }^{30}$ have recently demonstrated that alkali borate glasses are truly exceptional since large amounts (>60 mol \%) of $\mathrm{Sb}_{2} \mathrm{O}_{3}$ can be incorporated without devitrification. Nevertheless, to the best of our knowledge, borate glasses containing high concentration of $\mathrm{Sb}_{2} \mathrm{O}_{3}$ have not been studied in great detail for NLO device applications. Furthermore, the structural modifications in the sodium borate network with the addition of $\mathrm{Sb}_{2} \mathrm{O}_{3}$ have not been significantly explored. In view of the above, the present work aims at understanding the influence of $\mathrm{Sb}_{2} \mathrm{O}_{3}$ on network structure of the sodium borate glasses. In addition, efforts have been made to study the influence of structural changes on their enhancement of fs NLO properties. The structure of glass materials was evaluated by Raman and magic angle spinning (MAS) nuclear magnetic resonance (NMR: for nuclei ${ }^{11} \mathrm{~B}$ and ${ }^{23} \mathrm{Na}$ ) spectroscopy techniques. The NLO properties were investigated using $\sim 150 \mathrm{fs}$ pulses in the wavelength region of $750-880 \mathrm{~nm}$.

\section{EXPERIMENTAL METHODS}

2.1. Glass Preparation. The borate glass compositions $20 \mathrm{Na}_{2} \mathrm{O}-(80-x) \mathrm{B}_{2} \mathrm{O}_{3}-x \mathrm{Sb}_{2} \mathrm{O}_{3}$ (NBS) (in mol \%) with $x$ varying between 0 and $30 \mathrm{~mol} \%$ were synthesized through the conventional melt quenching technique. The samples were labeled as NBS-0, NBS-10, NBS-20, and NBS-30 corresponding to $0,10,20$, and $30 \mathrm{~mol} \%$ of $\mathrm{Sb}_{2} \mathrm{O}_{3}$ concentration present in the glass compositions. The appropriate amounts of ARgrade starting materials such as sodium carbonate $\left(\mathrm{Na}_{2} \mathrm{CO}_{3}\right.$, 99.99\%, SD Fine), boric acid $\left(\mathrm{H}_{3} \mathrm{BO}_{3}, 99.99 \%\right.$, SD Fine), and antimony trioxide $\left(\mathrm{Sb}_{2} \mathrm{O}_{3}, 99.99 \%\right.$, SD Fine) were weighed and mixed well. Finely ground starting materials were taken in porcelain crucibles and transferred to a high-temperature heating furnace (Heat Globe, Bengaluru). Initially, the batch was maintained at the temperature of $500{ }^{\circ} \mathrm{C}$ about $20 \mathrm{~min}$ for complete decarbonization; then, the temperature was raised slowly for melting the batch. Melting temperatures for compositions NBS-0, NBS-10, NBS-20, and NBS-30 were 1050, 940, 900, and $860{ }^{\circ} \mathrm{C}$, respectively. The melts were quenched by pouring between two preheated brass molds. The NBS-0 glass was annealed at $470{ }^{\circ} \mathrm{C}$ (around the $T_{\mathrm{g}}$ value), and the antimony-containing glasses were annealed at $350{ }^{\circ} \mathrm{C}$ for $4 \mathrm{~h}$

2.2. Physical and Optical Characterizations. The ultraviolet-visible-near-infrared (UV-vis-NIR) spectra of all of the polished samples were taken with the help of PerkinElmer Lambda-35 UV-visible spectrometer in the range of $200-1100 \mathrm{~nm}$ at room temperature with a resolution of 1 $\mathrm{nm}$. The density measurements of all of the bulk glasses were carried out by employing Archimedes' principle (analytical balance, OHAUS, model: PAG 213). Refractive index (n) measurements were done using Abbe's refractometer with sodium vapor lamp $(589.3 \mathrm{~nm})$ as light source. For the refractive index $(n)$ measurements, mono-bromonaphthalene was used as the contact layer between the sample and the prism of the refractometer. To quantify the contribution of $\mathrm{Sb}_{2} \mathrm{O}_{3}$ to the NLO properties of borate glasses, the Z-scan technique $^{31}$ was employed. The nonlinear absorption and refraction measurements of glasses were performed in openaperture (OA) and closed-aperture (CA) configurations, respectively. For the NLO measurements, $\sim 150$ fs pulses delivered by a Ti:sapphire laser (Chameleon, M/s Coherent; operating in the $680-1040 \mathrm{~nm}$ spectral range) at a repetition rate of $80 \mathrm{MHz}$ were utilized. The NLO measurements were performed at three spectral wavelengths of near-IR region, i.e., at 750,800 , and $880 \mathrm{~nm}$. In Z-scan measurements, the highly polished bulk glass samples with thickness of $\sim 1 \mathrm{~mm}$ were placed on a translation stage with $10 \mu \mathrm{m}$ resolution. A spatially 
filtered input Gaussian laser beam of $\sim 2 \mathrm{~mm}$ diameter was focused on the samples with the help of $10 \mathrm{~cm}$ convex lens. During the experiment, the glass sample was moved along the propagation axis (symbolized as $Z$ with $Z=0$ as the focal point), and at each position, the sample experiences a different peak intensity. Therefore, the position-dependent output intensity (or transmission) of the laser beam was collected using a thermal sensor placed after the sample.

2.3. Structural Characterization. X-ray diffraction (XRD) profiles of all NBS glasses were collected with the help of PANalytical Empyrean X-ray diffractometer equipped with a PIXcel ${ }^{3 \mathrm{D}}$ detector, using the $\mathrm{Cu} \mathrm{K} \alpha$ radiation $\left(\mathrm{Cu} \mathrm{K} \alpha_{1}\right.$ source, $\lambda=0.15406 \mathrm{~nm}, \mathrm{Cu} \mathrm{K} \alpha_{2}$ source, $\lambda=0.154443 \mathrm{~nm}$ ). The nickel filter was used to filter $\mathrm{Cu} \mathrm{K} \beta$ line. Diffraction data were collected in the Bragg-Brentano geometry with the detector in the line scanning mode. The test samples were prepared by pressing the powdered glasses on an amorphous silicon substrate, and data were collected from 10 to $80^{\circ}$ ( $2 \theta$ range) with a step size of $0.026^{\circ}$ (measurement time per step, $500 \mathrm{~s}$ ) at ambient temperature. Raman spectra (Bruker RFS100 FT-Raman) of all NBS glass samples were recorded in the range of $250-1000 \mathrm{~cm}^{-1}$ with a resolution of $4 \mathrm{~cm}^{-1}$, in which the samples were excited by an infrared (IR) laser (Nd:YAG) of power $350 \mathrm{~mW}$ operating at the wavelength of $1064 \mathrm{~nm}$.

MAS-NMR spectra were recorded for samples NBS-0, NBS20, and NBS-30 using a Bruker Avance III HD $700 \mathrm{MHz}$ narrow-bore spectrometer. A $4 \mathrm{~mm}$ triple-resonance MAS probe was selected at $185.20 \mathrm{MHz}\left({ }^{23} \mathrm{Na}\right)$ and $224.63 \mathrm{MHz}$ $\left({ }^{11} \mathrm{~B}\right)$ Larmor frequencies. The glasses were spun in $\mathrm{ZrO}_{2}$ rotors at a rate of $15 \mathrm{kHz} .{ }^{23} \mathrm{Na}$ MAS-NMR spectra were recorded with a $15^{\circ}$ excitation pulse corresponding to $0.35 \mu \mathrm{s}$ and a recycle delay of 2 s. ${ }^{11} \mathrm{~B}$ MAS-NMR spectra were recorded using a Hahn echo experiment with a $90^{\circ}$ excitation soft pulse of $6.25 \mu \mathrm{s}$ and a recycle delay of $2 \mathrm{~s}$. The chemical shifts are quoted in parts per million (ppm) using the following secondary references: saturated aqueous solution of $\mathrm{NaCl}(0$ ppm) and $0.1 \mathrm{M}$ aqueous solution of $\mathrm{H}_{3} \mathrm{BO}_{3}$ (19.6 ppm) for ${ }^{23} \mathrm{Na}$ and ${ }^{11} \mathrm{~B}$, respectively. The obtained MAS-NMR spectra were deconvoluted using the DMFit software. ${ }^{32}$

\section{RESULTS}

3.1. Physical and Optical Properties. The XRD patterns of the as-prepared NBS glasses are shown in Figure 1, and the data clearly reveal the amorphous nature. The density $(\rho)$ and molar volume $\left(V_{\mathrm{m}}\right)$ are the basic parameters to investigate the structural changes in the glass network since they are strongly influenced by structural compactness or softness, cross-linking, coordination number, etc. Therefore, the physical parameters,

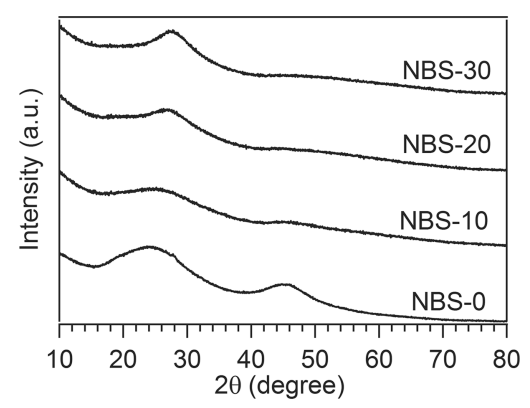

Figure 1. XRD profiles of the NBS glasses. such as density and molar volume along with electronic polarizability, molar refractivity, etc., have been evaluated for all of the glasses by using the expressions mentioned elsewhere $^{28}$ and are presented in Table 1. Figure 2 depicts the variation of density and molar volume of the bulk glasses due to the incorporation of $\mathrm{Sb}_{2} \mathrm{O}_{3}$. From Figure 2, it can be noted that both the density and molar volume of the bulk glasses increase with increasing $\mathrm{Sb}_{2} \mathrm{O}_{3}$ content. The enhancement in the density of the NBS glasses is attributed to the replacement of the greater-molecular-mass $\mathrm{Sb}_{2} \mathrm{O}_{3} \quad(291.52$ $\mathrm{amu})$ with the lower-molecular-mass $\mathrm{B}_{2} \mathrm{O}_{3}(69.62 \mathrm{amu})$ in the glass composition. The increase in molar volume can be attributed to larger ionic size of $\mathrm{Sb}^{3+}(76 \mathrm{pm})$ ions compared to that of $\mathrm{B}^{3+}(23 \mathrm{pm})$. The values of $\rho$ and $V_{\mathrm{m}}$ were found to be in the ranges of $2.281-3.426 \mathrm{~g} \mathrm{~cm}^{-3}$ and 29.850-35.576 $\mathrm{cm}^{3} \mathrm{~mol}^{-1}$, respectively. A similar behavior was also observed with the substitution of $\mathrm{Bi}_{2} \mathrm{O}_{3}$ for $\mathrm{B}_{2} \mathrm{O}_{3}$ in $15 \mathrm{Li}_{2} \mathrm{O}-15 \mathrm{~K}_{2} \mathrm{O}-$ $x \mathrm{Bi}_{2} \mathrm{O}_{3}-(65-x) \mathrm{B}_{2} \mathrm{O}_{3}: 5 \mathrm{~V}_{2} \mathrm{O}_{5},{ }^{33} \mathrm{ZnO}-\mathrm{Bi}_{2} \mathrm{O}_{3}-\mathrm{B}_{2} \mathrm{O}_{3},{ }^{34}$ and boron-silicon-bismuthate ${ }^{35}$ glass systems. The atomic packing density $\left(C_{\mathrm{g}}\right)$ values of all of the glasses were calculated using the relation mentioned in ref 36 and are presented in Table 1. It is evident that the $C_{\mathrm{g}}$ values decrease as a function of $\mathrm{Sb}_{2} \mathrm{O}_{3}$ content. The inset of Figure 2 shows the variation in refractive index $(n)$ with the composition, from which it is evident that $\mathrm{n}$ monotonically increases with increasing antimony content in the glasses. Figure 3 presents the UVvis absorption spectra of all of the glass samples. Prepared antimony-containing sodium borate glasses are optically transparent and exhibit good transparency window for wavelengths longer than $400 \mathrm{~nm}$. The glasses turn colorless to pale yellow as antimony content increases in the base glass. Figure 3 illustrates that the UV absorption edge shifted toward the longer wavelengths (red shift) with successive substitution of $\mathrm{Sb}_{2} \mathrm{O}_{3}$ for $\mathrm{B}_{2} \mathrm{O}_{3}$.

The optical absorption edge in the UV region is generally utilized to understand the electronic band structure and optical transitions in a material. In general, there are two kinds of optical transitions, namely, direct and indirect transitions, which can be estimated using fundamental absorption edge of linear absorption spectra of the material. Figure $4 a, b$ presents the plots of $(\alpha h \nu)^{2}$ versus $h \nu$ and $(\alpha h \nu)^{1 / 2}$ versus $h \nu$, respectively, where " $\alpha$ " is the absorption coefficient given by $\alpha(\lambda)=2.303\left(\frac{A}{t}\right), h$ is Plank's constant, " $A$ " is the energyindependent constant related to band tailing parameter, and " $\nu$ " is the frequency of photon. These plots are utilized to estimate the energy gaps of direct $\left(E_{\mathrm{g}}\right.$ dir $)$ and indirect $\left(E_{\mathrm{g}}^{\text {indir }}\right)$ allowed transitions according to the procedure mentioned elsewhere. ${ }^{37-39}$ The energy gap values of direct $\left(E_{\mathrm{g}}{ }^{\text {dir }}\right)$ and indirect $\left(E_{\mathrm{g}}\right.$ indir $)$ transitions are calculated by extrapolating the linear portions of the plots to reach $(\alpha h \nu)^{2}=0$ and $(\alpha h \nu)^{1 / 2}=$ 0 as shown in Figure 4a,b, respectively. The calculated direct and indirect optical band gap energies ( $E_{\mathrm{g}}$ dir and $E_{\mathrm{g}}$ indir, respectively) of NBS glass samples are tabulated in Table 1 , and the values are in the ranges of $3.99-3.25 \mathrm{eV}( \pm 0.02 \mathrm{eV})$ for $E_{\mathrm{g}}{ }^{\mathrm{ir}}$ and $3.26-2.78 \mathrm{eV}( \pm 0.02 \mathrm{eV})$ for $E_{\mathrm{g}}$ indir.

3.2. Raman Spectroscopy. Raman spectroscopy is one of the effective and often utilized tools to identify structural groups, environment, and dynamics of vitreous materials. Structural modifications with replacement of $\mathrm{B}_{2} \mathrm{O}_{3}$ by $\mathrm{Sb}_{2} \mathrm{O}_{3}$ were evaluated by collecting the Raman spectra for all of the bulk glass samples and are presented in Figure 5. The Raman 
Table 1. Physical and Optical Properties of $20 \mathrm{Na}_{2} \mathrm{O}-(80-x) \mathrm{B}_{2} \mathrm{O}_{3}-x \mathrm{Sb}_{2} \mathrm{O}_{3}$

\begin{tabular}{|c|c|c|c|c|}
\hline glasses & NBS-0 & NBS-10 & NBS-20 & NBS-30 \\
\hline \multicolumn{5}{|l|}{ physical properties } \\
\hline avg. molecular weight, $M\left(\mathrm{~g} \mathrm{~mol}^{-1}\right)$ & 68.09 & 90.28 & 112.47 & 134.66 \\
\hline density, $\rho\left(\mathrm{g} \mathrm{cm}^{-3}\right)( \pm 0.002)$ & 2.281 & 2.822 & 3.028 & 3.426 \\
\hline atomic packing density, $C_{g}( \pm 0.002)$ & 0.634 & 0.603 & 0.525 & 0.501 \\
\hline molar volume, $V_{\mathrm{m}}\left(\mathrm{cm}^{3} \mathrm{~mol}^{-1}\right)( \pm 0.002)$ & 29.850 & 31.888 & 33.708 & 35.576 \\
\hline refractive index, $n( \pm 0.001)$ & 1.512 & 1.684 & 1.746 & 1.854 \\
\hline dielectric constant, $\varepsilon( \pm 0.001)$ & 2.286 & 2.835 & 3.048 & 3.437 \\
\hline molar refractivity, $R_{M}\left(\mathrm{~cm}^{-3}\right)( \pm 0.002)$ & 8.927 & 12.050 & 13.594 & 15.894 \\
\hline electronic polarizability, $\alpha_{\mathrm{e}}\left(\times 10^{-24} \mathrm{~cm}^{3}\right)( \pm 0.002)$ & 3.538 & 4.776 & 5.388 & 6.299 \\
\hline \multicolumn{5}{|l|}{ optical properties } \\
\hline direct optical band gap, $E_{\mathrm{g}}^{\mathrm{dir}}(\mathrm{eV})( \pm 0.02)$ & 3.99 & 3.76 & 3.49 & 3.25 \\
\hline indirect optical band gap, $E_{\mathrm{g}}^{\text {indir }}(\mathrm{eV})( \pm 0.02)$ & 3.26 & 3.49 & 3.00 & 2.78 \\
\hline Urbach energy, $U_{\mathrm{E}}( \pm 0.02)^{\circ}$ & 0.36 & 0.38 & 0.41 & 0.47 \\
\hline
\end{tabular}

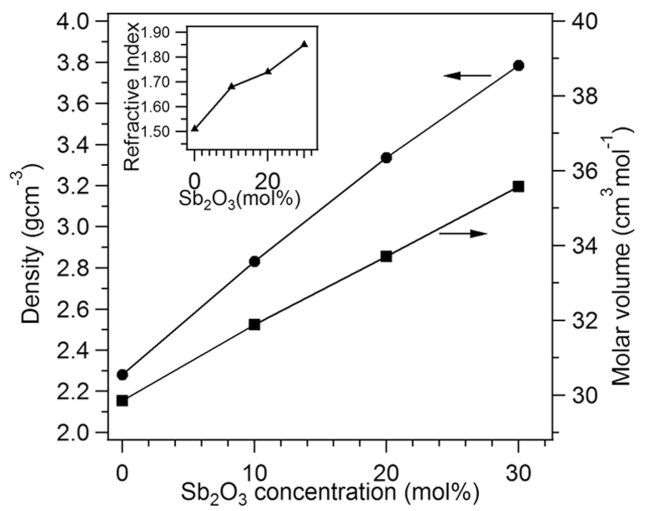

Figure 2. Composition dependence of density and molar volume in $20 \mathrm{Na}_{2} \mathrm{O}-(80-x) \mathrm{B}_{2} \mathrm{O}_{3}-x \mathrm{Sb}_{2} \mathrm{O}_{3}$ glasses; the inset shows the variation of refractive index as a function of $\mathrm{Sb}_{2} \mathrm{O}_{3}$ content in the glasses.

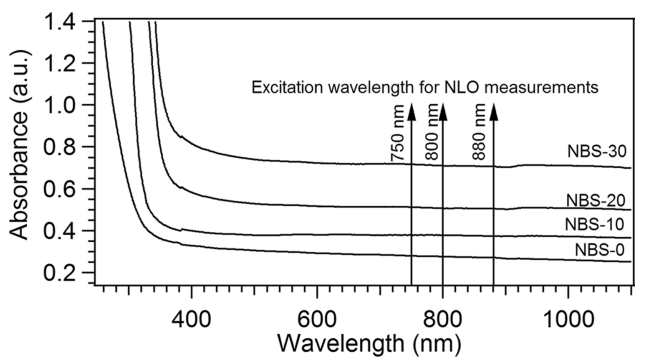

Figure 3. UV-vis absorption spectra of all NBS glass samples; the vertical lines inside the figure represent the wavelengths selected for NLO measurements.
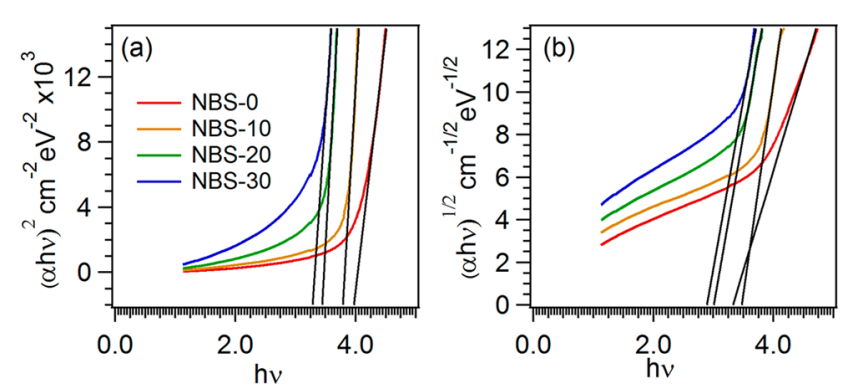

Figure 4. Tauc's plots used for the measurement of optical band gaps in NBS glasses: (a) direct band gap and (b) indirect band gap. spectra presented were processed for baseline correction according to the procedure mentioned in ref 40 .

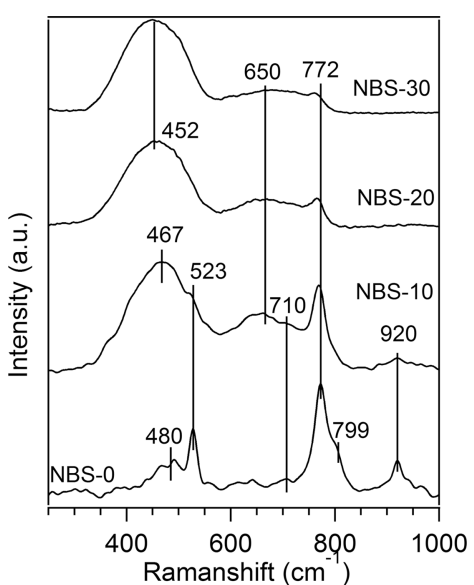

Figure 5. Compositional dependence of Raman spectra of $20 \mathrm{Na}_{2} \mathrm{O}-$ $(80-x) \mathrm{B}_{2} \mathrm{O}_{3}-x \mathrm{Sb}_{2} \mathrm{O}_{3}$ glasses.

3.2.1. Raman Spectra of NBS-O Glass. Pure vitreous $\mathrm{B}_{2} \mathrm{O}_{3}$ glass consists of boroxol rings along with some isolated $\mathrm{BO}_{3}$ units that are not part of boroxol ring. The presence of boroxol rings results in a vibration band at around $800 \mathrm{~cm}^{-1}$ in the Raman spectrum. It has been reported ${ }^{41}$ that the intensity of this band substantially decreases with increasing alkali metal cation concentration due to the conversion of the boroxol ring into $\mathrm{BO}_{4}$-containing six-membered rings (tetraborate, pentaborate, and triborategroups). The process of this conversion can be recognized with the development of the Raman vibrational band near $770 \mathrm{~cm}^{-1}$. This results in the formation of a complex network involving boroxol rings coupled with fourfold-coordinated boron in alkali borate glasses. ${ }^{42}$ The development of strong Raman band at $772 \mathrm{~cm}^{-1}$ as well as a shoulder at $802 \mathrm{~cm}^{-1}$ in NBS-0 glass evidences the formation of such complex networks. The band appearing at $802 \mathrm{~cm}^{-1}$ is indicative of breathing vibrations of boroxol rings, ${ }^{43}$ and the band at $772 \mathrm{~cm}^{-1}$ confirms that sodium ions favor the formation of $\mathrm{BO}_{4}$-containing six-membered rings (tetraborate, pentaborate, and triborategroups) at the expense of boroxol rings. ${ }^{44}$ The identification of specific structural group is also possible with the recognition of other associated vibrational bands present in the Raman spectrum. The simultaneous existence of bands at 930,770,640, and $480 \mathrm{~cm}^{-1}$ in the 
Raman spectra of NBS-0 glass clearly indicates that the pentaborate anionic groups $\left[\left(\mathrm{B}_{5} \mathrm{O}_{10}\right)^{5-}\right]$ are present in the glass structure. ${ }^{45}$ The presence of pentaborate groups in similar alkali borate glass compositions has also been reported. ${ }^{41-43}$ Based on these findings, the peak observed at $772 \mathrm{~cm}^{-1}$ is unambiguously assigned to the pentaborate groups. The observed band at $920 \mathrm{~cm}^{-1}$ is attributed to the vibration of planar orthoborate units. ${ }^{46}$

3.2.2. Raman Spectra of Antimony-Containing Glasses. The addition of antimony to the binary sodium borate glasses significantly changed the Raman spectra, indicating several modifications in the network. The band observed at $802 \mathrm{~cm}^{-1}$ in NBS-0 glass is completely absent in antimony-containing glasses. This clearly suggests that antimony might have entered and disrupted the boroxol rings in the alkali borate glass structure. This type of feature was also reported by Terashima et al. ${ }^{17}$ for $\mathrm{Sb}_{2} \mathrm{O}_{3}-\mathrm{B}_{2} \mathrm{O}_{3}$ binary glasses. Nevertheless, this observation was made only after the addition of $40 \mathrm{~mol} \%$ of $\mathrm{Sb}_{2} \mathrm{O}_{3}$. The Raman spectrum in the range of $200-750 \mathrm{~cm}^{-1}$ is very broad and is dominated by the $\mathrm{Sb}_{2} \mathrm{O}_{3}$ vibrational modes. ${ }^{47}$ It has been recently reported that the vitreous antimony materials exhibit a complex Raman spectrum consisting of three broad bands located at 605,465 , and $408 \mathrm{~cm}^{-1}$. 88 The $605 \mathrm{~cm}^{-1}$ band was assigned to the antisymmetric stretching vibrations of the $\mathrm{Sb}-\mathrm{O}-\mathrm{Sb}$ bridges. The 408 and $465 \mathrm{~cm}^{-1}$ Raman peaks were ascribed to the symmetric and antisymmetric stretching vibrations of the $\mathrm{SbO}_{3}$ pyramids, respectively. ${ }^{48}$ The presence of peaks observed at $460 \mathrm{~cm}^{-1}$ in antimony-containing glasses is therefore assigned to the stretching modes of $\mathrm{SbO}_{3}$ units. However, it should be highlighted at this point that the Raman spectrum of antimony-containing glasses is mainly dominated by $\mathrm{Sb}-\mathrm{O}$ vibrational modes and depressed the $\mathrm{B}-\mathrm{O}$ vibrational modes in the measured wavenumber range. Therefore, the peaks observed in NBS-10 cannot be readily assigned to specific vibrational bonds, although peaks at 523 and $710 \mathrm{~cm}^{-1}$ are detectable in NBS-10 glass. The peak that appeared at 772 $\mathrm{cm}^{-1}$ is clearly identifiable up to $30 \mathrm{~mol} \%$ of $\mathrm{Sb}_{2} \mathrm{O}_{3}$ addition. This indicates that the antimony-containing borate glasses have large concentration of pentaborate groups. The broadly pronounced Raman band centered at $\sim 650 \mathrm{~cm}^{-1}$ can be attributed to common vibration of $\mathrm{B}-\mathrm{O}-\mathrm{Sb}$ linkages formed due to the merging of $\mathrm{Sb}-\mathrm{O}-\mathrm{Sb}$ bridges with $\mathrm{B}-\mathrm{O}-\mathrm{B}$ linkages. ${ }^{49,50}$ This band is continuously upshifting with further addition of $\mathrm{Sb}_{2} \mathrm{O}_{3}$ into the glass composition. From Figure 5, it is also apparent that with increasing $\mathrm{Sb}_{2} \mathrm{O}_{3}$ concentration (above $10 \mathrm{~mol} \%$ ), the Raman band observed at $\sim 466 \mathrm{~cm}^{-1}$ shifted to lower values combined with an increase in the intensity.

3.3. MAS-NMR Spectroscopy. 3.3.1. ${ }^{11} B$ MAS-NMR. ${ }^{11} \mathrm{~B}$ MAS-NMR spectra of NBS glasses with varying concentrations of $\mathrm{Sb}_{2} \mathrm{O}_{3}$ are shown in Figure 6a. In borate glasses, boron usually exists in trigonal ( $\mathrm{B}^{3}$, coordination no: 3 ) and tetrahedral $\left(\mathrm{B}^{4}\right.$, coordination no: 4) units. ${ }^{43}{ }^{11} \mathrm{~B}$ MAS-NMR spectra of glasses show a good resolution of $\mathrm{B}^{3}$ and $\mathrm{B}^{4}$ species with two broad peaks centered at $\sim 15$ and $\sim 1 \mathrm{ppm}$, respectively. The relative concentrations of $\mathrm{B}^{3}$ and $\mathrm{B}^{4}$ units obtained after deconvolution of ${ }^{11} \mathrm{~B}$ MAS-NMR spectra (Figure 6a) and the corresponding parameters are presented in Table 2. For the good fitting of the spectra, the $\mathrm{B}^{3}$ peak was fitted with two peaks, namely, $\mathrm{B}^{3(\mathrm{I})}$ and $\mathrm{B}^{3(\mathrm{II})}$, while the $\mathrm{B}^{4}$ peak was fitted with two peaks for NBS- $0\left(B^{4(I)}\right.$ and $\left.B^{4(I I)}\right)$ and one peak for NBS-20 and NBS-30 $\left(\mathrm{B}^{4(\mathrm{I})}\right)$. For glass NBS-0, the

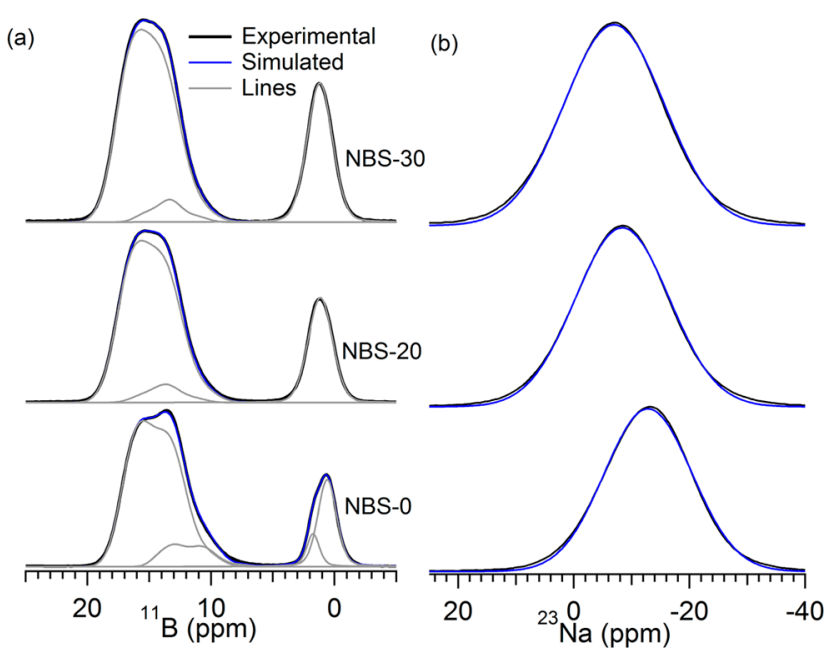

Figure 6. MAS-NMR spectra and their deconvolutions using DMFit software of NBS glasses: (a) ${ }^{11} \mathrm{~B}$ MAS-NMR spectra and (b) ${ }^{23} \mathrm{Na}$ MAS-NMR spectra of NBS glasses.

Table 2. ${ }^{11}$ B MAS-NMR Deconvolution Parameters of NBS Glasses

\begin{tabular}{cccrccc} 
glass & $\mathrm{B}^{4}(\%)$ & $\mathrm{B}^{n(x)}$ & $\begin{array}{c}\delta_{\text {iso }} \\
(\mathrm{ppm})\end{array}$ & $\begin{array}{c}\text { amount } \\
(\%)\end{array}$ & $\begin{array}{c}\mathrm{C}_{\mathrm{Q}} \\
(\mathrm{MHz})\end{array}$ & $\eta_{\mathrm{o}}$ \\
NBS-0 & 20.17 & $\mathrm{~B}^{3(\mathrm{I})}$ & 18.01 & 69.97 & 2.62 & 0.31 \\
& & $\mathrm{~B}^{3(\mathrm{II})}$ & 15.23 & 9.86 & 2.58 & 0.36 \\
& & $\mathrm{~B}^{4(\mathrm{I})}$ & 0.60 & 15.78 & & \\
NBS-20 & 21.75 & $\mathrm{~B}^{4(\mathrm{II})}$ & 1.75 & 4.39 & & \\
& & $\mathrm{~B}^{3(\mathrm{I})}$ & 18.31 & 72.63 & 2.61 & 0.26 \\
& & $\mathrm{~B}^{3(\mathrm{II})}$ & 16.50 & 5.63 & 2.08 & 0.95 \\
NBS-30 & \multirow{2}{*}{24.90} & $\mathrm{~B}^{4(\mathrm{I})}$ & 1.15 & 21.75 & & \\
& & $\mathrm{~B}^{3(\mathrm{I})}$ & 18.27 & 69.81 & 2.56 & 0.10 \\
& & $\mathrm{~B}^{3(\mathrm{II})}$ & 16.16 & 5.29 & 2.05 & 0.98 \\
& & $\mathrm{~B}^{4(\mathrm{I})}$ & 1.20 & 24.90 & & \\
\hline
\end{tabular}

lines $\mathrm{B}^{3(\mathrm{I})}$ and $\mathrm{B}^{3(\mathrm{II})}$ correspond to ring and nonring $\mathrm{B}^{3}$ structures. $^{51-53}$ In rest of the glass compositions, $\mathrm{B}^{3(\mathrm{I})}$ and $\mathrm{B}^{3(\mathrm{II})}$ correspond to symmetric and asymmetric $\mathrm{B}^{3}$ units. $^{51,54}$ The two lines of $\mathrm{B}^{4}$ for NBS-0 glass denoted by $\mathrm{B}^{4(\mathrm{I})}$ and $\mathrm{B}^{4(\mathrm{II})}$ might correspond to $\mathrm{B}^{4}$ units in different configurations such as diborate, triborate, pentaborate, etc. ${ }^{55}$ Svenson et al. ${ }^{43}$ also reported the presence of two $\mathrm{B}^{4}$ line shapes for a similar glass composition. With addition of $\mathrm{Sb}_{2} \mathrm{O}_{3}$, the fraction of $\mathrm{B}^{4}$ units increases (Table 2), which would have a positive effect on the glass stability. ${ }^{56}$ Nevertheless, Terashima et al. ${ }^{17}$ attempted to improve the nonlinear property of borate glasses through limiting the concentration of $\mathrm{B}^{4}$ units with the addition of $\mathrm{Sb}_{2} \mathrm{O}_{3}$. This is achieved owing to the strong covalent character of $\mathrm{Sb}-\mathrm{O}$ bonds. ${ }^{17,26,57}$

3.3.2. ${ }^{23} \mathrm{Na}$ MAS-NMR. The ${ }^{23} \mathrm{Na}$ MAS-NMR spectra and their deconvolution for all glasses are shown in Figure $6 \mathrm{~b}$, which display a broad resonance band. ${ }^{23} \mathrm{Na}$ MAS-NMR parameters after the decomposition are enlisted in Table 3.

Table $3 .{ }^{23} \mathrm{Na}$ MAS-NMR Deconvolution Parameters of NBS Glasses

\begin{tabular}{lccc}
\multicolumn{1}{c}{ glass } & $\delta_{\text {iso }}(\mathrm{ppm})$ & $\mathrm{C}_{\mathrm{Q}}(\mathrm{MHz})$ & $\eta_{\mathrm{o}}$ \\
NBS-0 & -6.94 & 2.557 & 0.86 \\
NBS-20 & -3.55 & 2.324 & 0.83 \\
NBS-30 & -2.58 & 2.275 & 0.70
\end{tabular}


Angeli et al. ${ }^{58}$ demonstrated that increasing $\mathrm{Na}-\mathrm{O}$ bond length decreases the ${ }^{23} \mathrm{Na}$ MAS-NMR chemical shift toward the lower ppm. It is known that $\mathrm{Na}-\mathrm{O}$ bond length is longer when sodium acts as a charge compensator than modifier cation. In the current glasses, with increasing $\mathrm{Sb}_{2} \mathrm{O}_{3}$ content, the ${ }^{23} \mathrm{Na}$ chemical shift increases.

3.4. Femtosecond NLO Properties. The sign and magnitude of nonlinear refraction and absorption coefficients of all glasses were determined by the $Z$-scan technique. In the present study, we performed nonlinear measurements in $\mathrm{OA}$ and $\mathrm{CA} Z$-scan modes for measuring the nonlinear absorption and refraction, respectively, in the spectral range of 750-880 $\mathrm{nm}$ with fs pulse excitation. Figure $7 \mathrm{a}$ depicts the $\mathrm{OA} Z$-scan
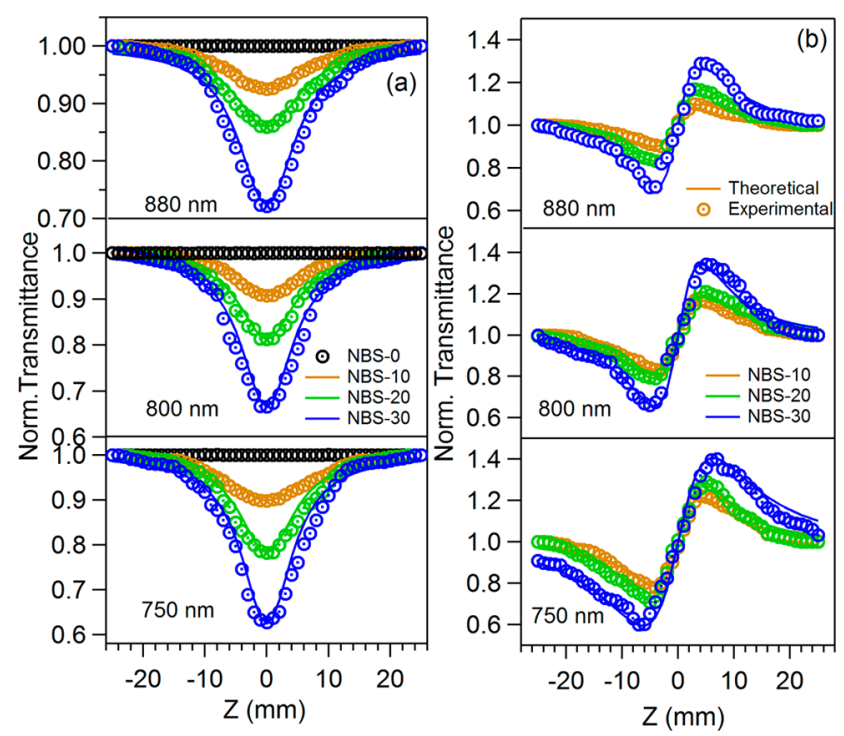

Figure 7. Z-scan signatures of NBS glasses: (a) open-aperture Z-scan plots and (b) closed-aperture $Z$-scan plots. The open circles represent the experimental data, and the solid lines are indicative of theoretically fitted data.

plots of sodium borate glasses with different concentrations of $\mathrm{Sb}_{2} \mathrm{O}_{3}$ at 750,800 , and $880 \mathrm{~nm}$. The peak intensities in the $Z$ scan measurements were in the range of $2 \times 10^{8}-4 \times 10^{8} \mathrm{~W}$ $\mathrm{cm}^{-2}$ for all of the samples and are similar at all of the wavelengths used in the present study. It is to be noted that even with this intensity, the photodarkening effect was not observed in the samples. From Figure 7a, it is evident that OA $Z$-scan plots demonstrate a dip at focal point. This could be considered as a signature of reverse saturable absorption (RSA) property in the antimony-containing glasses. In general, in $\mathrm{OA} Z$-scan mode, the output transmittance of the laser beam decreases and becomes minimum at focal point $(Z=0)$ and hence results a valley at focal point, as shown in Figure $7 \mathrm{a}$. Nevertheless, the observed RSA kind of nonlinearity indicates the simultaneous absorption of two or more photons (i.e., 2PA, 3PA, and so on). To identify the number of photons absorbed for observed nonlinearity, we have considered the general multiphoton absorption (MPA) equation ${ }^{59}$

$$
\begin{aligned}
& T_{\mathrm{OA}}(n \mathrm{PA})= \\
& \frac{1}{\left[1+(n-1) \alpha_{n} L_{\mathrm{eff}}\left(I_{00} /\left(1+\left(Z / Z_{0}\right)^{2}\right)\right)^{n-1}\right]^{1 / n-1}}
\end{aligned}
$$

where $\alpha_{n}$ is the effective multiphoton absorption coefficient (" $n$ " is the order or absorption process, $n=2$ for $2 \mathrm{PA}, n=3$ for 3PA, and etc.), $I_{00}$ is the peak intensity of the laser beam, $L_{\text {eff }}=\frac{1-\mathrm{e}^{-(n-1) \alpha_{0} L}}{\alpha_{0}}$ is the effective path length, $Z$ is the position of the sample, $Z_{0}=\pi \omega_{0}^{2} / \lambda$ is the Rayleigh range, $\omega_{0}$ is the beam waist at $Z=0$ (focal point), and $\lambda$ is the excitation wavelength.

Experimental OA $Z$-scan data of all of the glasses were best fitted with eq 1 for $n=2$, and the obtained $\alpha_{2}$ values are provided in Table 4 for different wavelengths. The errors mentioned in the data arise mainly from errors in the estimation of beam waist at focus and the resulting errors in peak intensities along with fitting errors. From Figure $7 \mathrm{a}$, it is evident that the incorporation of $\mathrm{Sb}_{2} \mathrm{O}_{3}$ yielded the RSA nonlinearity in the NBS glasses since NBS-0 did not demonstrate any dip at focal point. A similar kind of RSA behavior is also observed in other borate glass systems. $4,5,18,19$ Figure $7 \mathrm{~b}$ illustrates the $\mathrm{CA} Z$-scan curves of antimonycontaining glasses with different concentrations of $\mathrm{Sb}_{2} \mathrm{O}_{3}$ at 750,800 , and $880 \mathrm{~nm}$. From Figure $7 \mathrm{~b}$, it is clear that the prefocal dip is followed by a postfocal peak, and it is a clear signature for a positive nonlinear refractive index. This positive nonlinear refraction is due to self-focusing effect. ${ }^{4}$ The nonlinear refractive index $\left(n_{2}\right)$ value can be estimated by using the phase difference value $\left(\Delta \Phi_{0}\right)$ and is given by

$$
n_{2}\left(\mathrm{~m}^{2} \mathrm{~W}^{-1}\right)=\frac{\left|\Delta \Phi_{0}\right| \lambda}{2 \pi I_{00} L_{\text {eff }}}
$$

The phase difference value $\left(\Delta \Phi_{0}\right)$ is, therefore, obtained by fitting the CA $Z$-scan experimental data (dotted lines in Figure $7 \mathrm{~b}$ ) using eq 3 (solid lines in Figure $7 \mathrm{~b}$ ).,

$$
T_{\mathrm{CA}}=1+\frac{4 \Delta \Phi_{0}\left(Z / Z_{0}\right)}{\left[1+\left(Z / Z_{0}\right)^{2}\right]\left[9+\left(Z / Z_{0}\right)^{2}\right]}
$$

where $\Delta \Phi_{0}$ is the phase difference of the laser beam caused

\begin{tabular}{|c|c|c|c|c|c|c|c|}
\hline glass & $\lambda(\mathrm{nm})$ & $\alpha\left(\mathrm{cm}^{-1}\right)$ & $\alpha_{2}\left(\mathrm{~cm}(\mathrm{GW})^{-1}\right)$ & $n_{2}\left(\times 10^{-18} \mathrm{~m}^{2} \mathrm{~W}^{-1}\right)$ & $\operatorname{Re} \chi^{(3)}\left(\times 10^{-13}\right.$ esu $)$ & $\operatorname{Im} \chi^{(3)}\left(\times 10^{-13} \mathrm{esu}\right)$ & $\chi^{(3)}\left(\times 10^{-13} \mathrm{esu}\right)$ \\
\hline \multirow[t]{3}{*}{ NBS-10 } & 750 & 10.69 & $0.21( \pm 0.02)$ & $0.38( \pm 0.05)$ & 2.73 & 0.90 & 2.87 \\
\hline & 800 & 10.63 & $0.14( \pm 0.01)$ & $0.21( \pm 0.03)$ & 1.51 & 0.64 & 1.64 \\
\hline & 880 & 10.48 & $0.07( \pm 0.001)$ & $0.16( \pm 0.02)$ & 1.15 & 0.35 & 1.2 \\
\hline \multirow[t]{3}{*}{ NBS-20 } & 750 & 14.38 & $0.57( \pm 0.05)$ & $0.62( \pm 0.09)$ & 4.79 & 2.63 & 5.46 \\
\hline & 800 & 14.25 & $0.46( \pm 0.04)$ & $0.51( \pm 0.07)$ & 3.94 & 2.26 & 4.54 \\
\hline & 880 & 14.18 & $0.39( \pm 0.03)$ & $0.47( \pm 0.07)$ & 3.63 & 2.11 & 4.19 \\
\hline \multirow{2}{*}{ NBS-30 } & 800 & 19.95 & $0.82( \pm 0.08)$ & $0.87( \pm 0.13)$ & 7.58 & 4.55 & 8.83 \\
\hline & 880 & 19.85 & $0.74( \pm 0.07)$ & $0.72( \pm 0.10)$ & 6.27 & 4.51 & 7.72 \\
\hline
\end{tabular}
due to nonlinear refraction. The obtained $n_{2}$ values of NBS glasses are reported in Table 4. Similar positive nonlinear

Table 4. Summary of NLO Coefficients of NBS Glasses Obtained from the fs Z-Scan Experiments 
Table 5. NLO Coefficients of Some Selected Glass Compositions

\begin{tabular}{|c|c|c|c|c|}
\hline glass composition & $\begin{array}{l}\text { wavelength and pulse } \\
\text { sizes }\end{array}$ & $\begin{array}{l}\text { two-photon absorption coefficients } \\
\qquad\left(\alpha_{2}, \mathrm{~cm}(\mathrm{GW})^{-1}\right)\end{array}$ & $\begin{array}{l}\text { nonlinear refractive index } \\
\left(n_{2}, \mathrm{~m}^{2} \mathrm{~W}^{-1}\right)\end{array}$ & reference \\
\hline \multirow[t]{3}{*}{$10 \mathrm{CaO}-35 \mathrm{Bi}_{2} \mathrm{O}_{3}-55 \mathrm{~B}_{2} \mathrm{O}_{3}$} & $800 \mathrm{~nm}(100 \mathrm{fs})$ & $2.8 \times 10^{-2}$ & & 19 \\
\hline & $532 \mathrm{~nm}(30 \mathrm{ps})$ & 1.3 & & 19 \\
\hline & $532 \mathrm{~nm}(6 \mathrm{~ns})$ & & $1.6 \times 10^{-16}$ & 19 \\
\hline \multirow[t]{3}{*}{$10 \mathrm{SrO}-35 \mathrm{Bi}_{2} \mathrm{O}_{3}-55 \mathrm{~B}_{2} \mathrm{O}_{3}$} & $800 \mathrm{~nm}(100 \mathrm{fs})$ & $3.4 \times 10^{-2}$ & & 19 \\
\hline & $532 \mathrm{~nm}(30 \mathrm{ps})$ & 2.4 & & 19 \\
\hline & $532 \mathrm{~nm}(6 \mathrm{~ns})$ & & $3.2 \times 10^{-16}$ & 19 \\
\hline $10 \mathrm{BaO}-35 \mathrm{Bi}_{2} \mathrm{O}_{3}-55 \mathrm{~B}_{2} \mathrm{O}_{3}$ & $532 \mathrm{~nm}(6 \mathrm{~ns})$ & & $4.7 \times 10^{-16}$ & 19 \\
\hline \multirow{2}{*}{$45 \mathrm{Bi}_{2} \mathrm{O}_{3}-3 \mathrm{ZnO}-25 \mathrm{~B}_{2} \mathrm{O}_{3}$} & $800 \mathrm{~nm}(110 \mathrm{fs})$ & 1.04 & $1.5 \times 10^{-19}$ & 4 \\
\hline & $532 \mathrm{~nm}(30 \mathrm{ps})$ & 24.6 & & 4 \\
\hline \multirow[t]{2}{*}{ fused silica } & $1064 \mathrm{~nm}$ & & $2.7 \times 10^{-20}$ & 62 \\
\hline & $355 \mathrm{~nm}$ & $1.25 \times 10^{-3}$ & $2.5 \times 10^{-20}$ & 62 \\
\hline \multirow[t]{2}{*}{ BK-10 (borosilicate crown glass) } & $1064 \mathrm{~nm}$ & & $2.8 \times 10^{-20}$ & 62 \\
\hline & $355 \mathrm{~nm}$ & 0.0055 & $1.7 \times 10^{-20}$ & 62 \\
\hline \multirow[t]{3}{*}{$25 \mathrm{Bi}_{2} \mathrm{O}_{3}-37.5 \mathrm{ZnO}-37.5 \mathrm{~B}_{2} \mathrm{O}_{3}$} & $1064 \mathrm{~nm}(100 \mathrm{ps})$ & $<0.02$ & $1 \times 10^{-18}$ & 63 \\
\hline & $800 \mathrm{~nm}(150 \mathrm{fs})$ & $<0.01$ & $2.9 \times 10^{-19}$ & 63 \\
\hline & $532 \mathrm{~nm}(80 \mathrm{ps})$ & 5.5 & $3 \times 10^{-18}$ & 63 \\
\hline \multirow{3}{*}{$12.5 \mathrm{Bi}_{2} \mathrm{O}_{3}-43.5 \mathrm{ZnO}-43.5 \mathrm{~B}_{2} \mathrm{O}_{3}$} & $1064 \mathrm{~nm}(100 \mathrm{ps})$ & $<0.02$ & $<5 \times 10^{-19}$ & 63 \\
\hline & $800 \mathrm{~nm}(150 \mathrm{fs})$ & $<0.01$ & $1.3 \times 10^{-19}$ & 63 \\
\hline & $532 \mathrm{~nm}(80 \mathrm{ps})$ & 1.5 & $1.8 \times 10^{-18}$ & 63 \\
\hline
\end{tabular}

refraction results are also observed for other borate glass system. ${ }^{4,5,61}$ Similar to 2PA $\left(\alpha_{2}\right)$ coefficient, the $n_{2}$ values also increased with the addition of $\mathrm{Sb}_{2} \mathrm{O}_{3}$, and a highest value was observed for the NBS-30 glass. All of the values of $\alpha_{2}$ and $n_{2}$ at different excitation wavelengths for all NBS glasses are enlisted in Table 4. It is observed that the $\alpha_{2}$ and $n_{2}$ increased with increasing antimony contents in NBS glasses or, in other words, both the $\alpha_{2}$ and $n_{2}$ increase with decreasing energy gap. From Table 4 , it is also evident that both $\left(\alpha_{2}\right.$ and $\left.n_{2}\right)$ show monotonous increase as the energy of excitation wavelength approaches the energy gap, and this effect known as resonance enhancement of nonlinearity usually occurs when the frequency (energy) of excited laser radiation approaches the linear absorption of the material. ${ }^{5}$ Further, the $\alpha_{2}$ and $n_{2}$ values of the selected glass compositions are enlisted in Table 5. 4,19,62,63 The intensity-dependent NLO properties were measured using OA $Z$-scan mode at three spectral regions for NBS-20 and NBS-30 glasses. The variation of $\alpha_{2}$ with respect to input intensities is shown in Figure 8 , and it is evident that the changes were within the experimental error suggesting the absence of other types of nonlinearities (highorder or excited-state absorption induced).

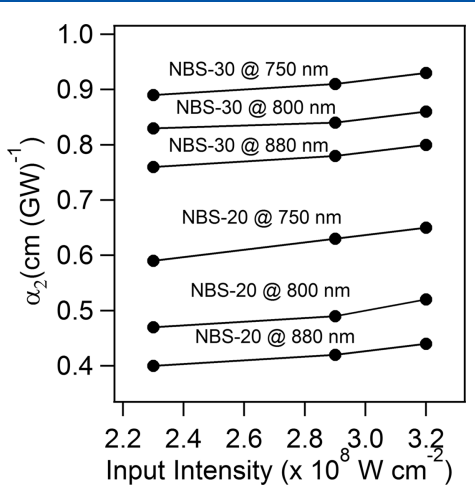

Figure 8. Intensity dependence of two-photon absorption coeffcient $\left(\alpha_{2}\right)$ of NBS-20 and NBS-30 glasses.
The real and imaginary parts of $\chi^{(3)}$ can be evaluated using the following equations ${ }^{64}$

$$
\begin{aligned}
& \operatorname{Re} \chi^{(3)}(\mathrm{esu})=\frac{\varepsilon_{0} c^{2} n_{0}^{2}}{\pi} n_{2}\left(\mathrm{~m}^{2} / \mathrm{W}\right) \\
& \operatorname{Im} \chi^{(3)}(\mathrm{esu})=\frac{\lambda \varepsilon_{0} c^{2} n_{0}^{2}}{4 \pi^{2}} \alpha_{2}(\mathrm{~m} / \mathrm{W})
\end{aligned}
$$

where $c, \varepsilon_{0}$, and $n_{0}$ are the velocity of light, permittivity of vacuum, and linear refractive index of the glass, respectively. The total $\chi^{(3)}$ can be evaluated using the relation

$$
\left|\chi^{(3)}\right|(\mathrm{esu})=\left\{\left(\operatorname{Re} \chi^{(3)}\right)^{2}+\left(\operatorname{Im} \chi^{(3)}\right)^{2}\right\}^{1 / 2}
$$

All of the evaluated real and imaginary nonlinear susceptibility values along with the total nonlinear susceptibility ones are also presented in Table 4. It is clear that the obtained $\chi^{(3)}$ values of the present NBS glasses are 1 order of magnitude greater than those of $\mathrm{Sb}_{2} \mathrm{O}_{3}-\mathrm{B}_{2} \mathrm{O}_{3}$ binary glasses. ${ }^{17}$ Further, Lin et al. ${ }^{65}$ measured the nonlinear response time of $\mathrm{Bi}_{2} \mathrm{O}_{3}$ $\mathrm{B}_{2} \mathrm{O}_{3}-\mathrm{SiO}_{2}$ glasses via optical Kerr shutter experiment at 800 $\mathrm{nm}$ and by utilizing $30 \mathrm{fs}$ pulses at a repetition rate of $1 \mathrm{kHz}$, and the estimated response time was $<90$ fs. Sugimoto et al. ${ }^{66}$ studied the temporal dynamics of glasses consisting of $\mathrm{Bi}_{2} \mathrm{O}_{3}$ through degenerate four-wave mixing method at $810 \mathrm{~nm}$ using $200 \mathrm{fs}$ laser pulses and found that the studied glasses show electronic response below 200 fs. Similarly, $\mathrm{Yu}$ et al. ${ }^{67}$ evaluated the optical nonlinearity of HMO glasses through the optical Kerr gate method and found that the temporal response was faster than 350 fs. Falcão-Filho et al. ${ }^{27}$ measured the response time of antimony orthophosphate glasses, in which the correlation signals between pump and probe pulses represent ultrafast response $(<100 \mathrm{fs})$ for all glass compositions. Their results clearly demonstrated that the observed nonlinearity arises predominantly from electronic polarization. The $Z$-scan experiments are single-beam experiments in which the pumping and probing of the glass samples are done by the same laser pulse. In the present investigation, the optical nonlinearity was obtained with $150 \mathrm{fs}, 80 \mathrm{MHz}$ repetition rate laser pulses, and this signifies that the nonlinearity has a 
femtosecond (ultrafast) component, and due to high repetition rate (and small absorption at the excited wavelengths), there could be thermal component also.

\section{DISCUSSION}

4.1. Glass Structure. The addition of modifier oxide to the $\mathrm{B}_{2} \mathrm{O}_{3}$ system initially converts the $\mathrm{B}^{3}$ (boroxol rings) units into $\mathrm{B}^{4}$ units, and the formation of NBOs initiates only at higher modifier concentrations. For the well-known sodium borate system, it is postulated that the addition of sodium results in the formation of NBOs only for $R\left(R=\mathrm{R}_{2} \mathrm{O} / \mathrm{B}_{2} \mathrm{O}_{3}\right.$, where $\mathrm{R}_{2} \mathrm{O}$ is the alkali oxide) greater than 0.5 . For $R \leq 0.5$, all of the alkali cations act only as charge compensators. It is therefore expected that the presence of NBOs in NBS-0 glass $(R=0.25)$ should be zero. The Raman spectrum for NBS-0 glass clearly indicates the presence of pentaborate groups consisting of $\mathrm{BO}_{3}$ units and $\mathrm{BO}_{4}$ units. Nevertheless, the Raman spectrum does not reveal the presence of NBO-containing borate units in NBS-0 glass. The NMR spectrum, however, provides the experimental fraction of $\mathrm{B}^{4}$ units $(\sim 0.20)$ that is slightly below the $R(0.25)$ value. This indicates that small concentrations of $\mathrm{Na}$ cations are also involved in the formation of NBOs, which could not be determined due to the broad $\mathrm{B}^{3}$ peak. The concentration of $\mathrm{NBO}$ s calculated based on the equation mentioned elsewhere ${ }^{68}$ assuming that all NBOs are associated with $\mathrm{BO}_{3}$ sites showed nearly $3 \%$ of oxygens present as NBO in NBS-0 glass. Further, the appearance of a small intense Raman peak at $920 \mathrm{~cm}^{-1}$ also indicates the presence of a small fraction of isolated $\mathrm{BO}_{3}{ }^{3-}$ boron units in NBS-0 glass.

The addition of $\mathrm{Sb}_{2} \mathrm{O}_{3}$ to NBS-0 glass slightly increased the fraction of $\mathrm{B}^{4}$ units. This cannot be attributed to the variation of $\mathrm{Na} / \mathrm{B}$ ratio with the addition of $\mathrm{Sb}_{2} \mathrm{O}_{3}$. If this was the case, the expected amounts of $\mathrm{B}^{4}$ units should be $\sim 25,33$, and $40 \%$ for NBS-0, NBS-20, and NBS-30, respectively. However, this is not in agreement with the experimental values (Table 2). Therefore, the structural changes upon the addition of $\mathrm{Sb}_{2} \mathrm{O}_{3}$ are complex.

The structures of $\mathrm{Sb}_{2} \mathrm{O}_{3}-\mathrm{B}_{2} \mathrm{O}_{3}$ glass have been considered to be $\mathrm{SbO}_{3}$ trigonal pyramid. Nevertheless, Masuda et al., ${ }^{69}$ using X-ray fluorescence, found that $\mathrm{Sb}^{3+}$ (in trigonal pyramids) and $\mathrm{Sb}^{5+}$ (in octahedral form) were both present in nearly equal amounts in binary alkali and alkaline earth antimonite glasses. It is interesting to note that the $\mathrm{BO}_{4}$ units, even though their fractions are very small, were also found in the $\mathrm{Sb}_{2} \mathrm{O}_{3}-\mathrm{B}_{2} \mathrm{O}_{3}$ glass system as in the $\mathrm{Bi}_{2} \mathrm{O}_{3}-\mathrm{B}_{2} \mathrm{O}_{3}$ system. ${ }^{17}$ On the other hand, $\mathrm{BO}_{4}$ units were not found in $\mathrm{GeO}_{2}-\mathrm{B}_{2} \mathrm{O}_{3}$ glasses for the $\mathrm{GeO}_{2}$ ranges from 15 to $100 \mathrm{~mol} \mathrm{\%}{ }^{17}$ This clearly indicates that the $\mathrm{Sb}$ cations play the role of charge compensator in $\mathrm{Sb}_{2} \mathrm{O}_{3}-\mathrm{B}_{2} \mathrm{O}_{3}$ glass system. However, the type of charge compensating species in $\mathrm{Sb}_{2} \mathrm{O}_{3}-\mathrm{B}_{2} \mathrm{O}_{3}$ glass is not yet clear. It has been reported that small part of $\mathrm{Sb}_{2} \mathrm{O}_{3}$ transforms into $\mathrm{Sb}_{2} \mathrm{O}_{5}$ during the melting process owing to the interaction with oxygen in air. ${ }^{70} \mathrm{Sb}_{2} \mathrm{O}_{5}$ consists of distorted corner- and edge-sharing $\mathrm{Sb}^{5+} \mathrm{O}_{6}$ octahedra. $^{71-73}$ Masuda et al. ${ }^{69}$ concluded that both $\mathrm{Sb}^{3+}$ and $\mathrm{Sb}^{5+}$ were present in nearly equal amounts in the binary alkali and alkaline earth antimonite glasses. Holland et al. ${ }^{26}$ further confirmed the presence of $\mathrm{Sb}^{5+}$ and $\mathrm{Sb}^{3+}$ in binary $\mathrm{Sb}_{2} \mathrm{O}_{3}-\mathrm{B}_{2} \mathrm{O}_{3}$ glasses through Mossbauer spectroscopy. It was also identified that the percentage of $\mathrm{Sb}^{5+}$ cations increased with monotonic increase of $\mathrm{Sb}_{2} \mathrm{O}_{3}$. Therefore, the charge compensation for the formation of $\left[\mathrm{BO}_{4}\right]^{-}$is only due to the presence of $\mathrm{Sb}^{5+} \mathrm{O}_{6}$ octahedra. ${ }^{26}$ The ${ }^{23} \mathrm{Na}$ MAS-NMR chemical shift is oppositely related to the $\mathrm{Na}-\mathrm{O}$ bond length and/or coordination number. It decreases with the increasing average $\mathrm{Na}-\mathrm{O}$ bond length. The increasing percentage of $\mathrm{Na}$ as charge compensators results in larger $\mathrm{Na}-$ $O$ distances and thus decreases the chemical shift. In the current glasses, the increase in sodium chemical shift (Figure $6 \mathrm{~b}$ and Table 3) with increase in $\mathrm{Sb}_{2} \mathrm{O}_{3}$ indicates the role of sodium as charge compensator decreases. This is substantiated by the occurrence of asymmetric $\mathrm{B}^{3}$ units in the antimonycontaining glasses (Figure 6a and Table 2). The change in $\mathrm{Na}$ cation's role from charge compensation to NBOs resulted in the formation of asymmetric $\mathrm{B}^{3}$ units. Further, Raman spectra (Figure 5) also show decrease in the three-membered boroxol rings with the addition of $\mathrm{Sb}_{2} \mathrm{O}_{3}$.

It is known that the $\mathrm{Sb}_{2} \mathrm{O}_{3}$ is a conditional glass former and it forms the glass in the presence of modifiers or other glass formers (like $\mathrm{B}_{2} \mathrm{O}_{3} / \mathrm{P}_{2} \mathrm{O}_{5} / \mathrm{TeO}_{2} / \mathrm{GeO}_{2}$ ). The triangular $\mathrm{SbO}_{3}$ pyramids with the three oxygen atoms at corners $(\mathrm{Sb}-\mathrm{O}$ bond lengths as $0.2023,0.2019$, and $0.1977 \mathrm{~nm}$ ) and the lone pair of electrons at the fourth corner are the main building blocks in the antimony glass. ${ }^{50}$ The presence of $650 \mathrm{~cm}^{-1}$ band in Raman spectrum indicates that the third oxygen in each $\mathrm{SbO}_{3}$ units is linked with boron units and formed the $\mathrm{Sb}-\mathrm{O}-\mathrm{B}$ linkages. ${ }^{74}$ The similarity between the electronegativities of boron (2.0) and antimony (1.9) is also responsible for the formation of such $\mathrm{Sb}-\mathrm{O}-\mathrm{B}$ linkages in antimony borate glasses. $^{26}$

4.2. Structure-Physical Properties. The substitution of antimony for boron in the parent glass has a significant effect on the structure and properties of glass. The density and molar volume of NBS glasses increase with $\mathrm{Sb}_{2} \mathrm{O}_{3}$. Nevertheless, the atomic packing density decreases with increase in $\mathrm{Sb}_{2} \mathrm{O}_{3}$ in the composition. The increase in density with incorporation of $\mathrm{Sb}_{2} \mathrm{O}_{3}$ for $\mathrm{B}_{2} \mathrm{O}_{3}$ in the glass composition is a predictable result since $\mathrm{Sb}_{2} \mathrm{O}_{3}$ has greater molecular mass compared to $\mathrm{B}_{2} \mathrm{O}_{3}$. The enhancement in molar volume of the glasses with respect to $\mathrm{Sb}_{2} \mathrm{O}_{3}$ content is attributed to the slight increase in the percentage of oxygen atoms due to $\mathrm{Sb}^{3+} \rightarrow \mathrm{Sb}^{5+}$ reaction and larger $\mathrm{Sb}$ ionic radii compared to boron $\left(\mathrm{O}^{2-}: 140 \mathrm{pm}, \mathrm{Sb}^{3+}\right.$ : $76 \mathrm{pm}, \mathrm{Sb}^{5+}: 60 \mathrm{pm}, \mathrm{Na}^{+}: 102 \mathrm{pm}$, and $\left.\mathrm{B}^{3+}: 23 \mathrm{pm}\right){ }^{75}$ The atomic packing density values showed decreasing trend with increasing $\mathrm{Sb}_{2} \mathrm{O}_{3}$ content, which is in accordance with molar volume trend. Thus, atomic density and molar volume are inversely related.

4.3. Structure-Optical Properties. It has been reported that the presence of large and polarizable ions increases the NLO properties of the glasses. This is possibly attributed to the large electronic hyperpolarizability character of NBOs compared to bridging oxygens. ${ }^{76}$ The decrease in optical band gap with the addition of $\mathrm{Sb}_{2} \mathrm{O}_{3}$ suggests that the content of NBOs is increased in the glass matrix. ${ }^{11}$ The ${ }^{23} \mathrm{Na}$ MASNMR chemical shift, which shifts toward higher ppm, also indicates that the role of $\mathrm{Na}$ as a charge compensator decreases. This supports the increasing role of $\mathrm{Na}^{+}$cation as a modifier, which generally converts the bridging oxygen into the NBO, in glass matrix. Franco et al. ${ }^{47}$ investigated the influence of $\mathrm{Sb}_{2} \mathrm{O}_{3}$ on the plasmonic properties of copper nanoparticles and explained that during the melting process in the temperature range of $500-800{ }^{\circ} \mathrm{C}$, the $\mathrm{Sb}$ undergoes a phase transition through oxidation of $\mathrm{Sb}$ species, resulting in $\mathrm{Sb}^{5+}$ from $\mathrm{Sb}^{3+}$ (i.e., $\mathrm{Sb}^{3+} \rightarrow \mathrm{Sb}^{5+}+2 \mathrm{e}^{-}$). Nonetheless, these lone pair of electrons $\left(5 \mathrm{~s}^{2}\right)$ of $\mathrm{Sb}^{3+}$ cause a high polarization of the $\mathrm{O}^{2-}$ anion and increase the total electronic polarizability. ${ }^{29}$ Further, the $\mathrm{Sb}$ atoms having five valence electrons in the outer 
electronic shell undergo distortion in the presence of an applied optical field. Thus, large charge displacement can occur, resulting in the greater polarizability of $\mathrm{Sb}^{5+}$ ion. ${ }^{77}$ Such significant displacements produce anharmonic effects, resulting in large cubic hyperpolarizabilities. ${ }^{78}$ Interestingly, in oxide glasses, the molar refraction mainly depends on $\mathrm{O}^{2-}$ ions, and this molar refraction is in turn directly related to $\chi^{(3)}{ }^{66}$ Moreover, it is known that the $\mathrm{O}^{2-}$ ions are affected by surrounding cations. The neighboring cations with large ionic radii enlarge the molar refraction of glasses because the ion refraction of the cation itself increases and the asymmetry of the electric field around the $\mathrm{O}^{2-}$ ions becomes larger. The antimony ions have coordination numbers of 5 and 3 in NBS glasses, and their ionic radii are large compared to that of boron. Therefore, the present NBS glasses containing $\mathrm{Sb}_{2} \mathrm{O}_{3}$ exhibit large molar refraction. ${ }^{66}$ Therefore, the enhancement in $\mathrm{NLO}$ coefficients with respect to $\mathrm{Sb}_{2} \mathrm{O}_{3}$ can be attributed to the hyperpolarizability of $\mathrm{Sb}^{3+}$ and $\mathrm{Sb}^{5+}$ ions. Further, the ${ }^{11} \mathrm{~B}$ MAS-NMR studies, band gap analysis, and the physical properties of the present glasses also clearly evidence the increase of NBOs with gradual substitution of $\mathrm{B}_{2} \mathrm{O}_{3}$ by $\mathrm{Sb}_{2} \mathrm{O}_{3}$; hence, it can be concluded that the NBOs also contributed to observed NLO coefficients. The $\mathrm{N}_{4}$ values of present NBS glasses estimated using ${ }^{11} \mathrm{~B}$ MAS-NMR are greater than those of $\mathrm{Sb}_{2} \mathrm{O}_{3}-\mathrm{B}_{2} \mathrm{O}_{3}$ binary glasses. This indicates that the formation of NBO due to donation of oxygen of metal oxide to $\mathrm{BO}_{3}$ is greater in the studied glasses compared to binary $\mathrm{Sb}_{2} \mathrm{O}_{3}-\mathrm{B}_{2} \mathrm{O}_{3}$ glasses. ${ }^{17,26}$ From the data presented in Table 4, one can note that larger variation of $n_{2}$ than $\alpha_{2}$ as a function of $\mathrm{Sb}_{2} \mathrm{O}_{3}$ implies that, possibly, the nonlinear index of refraction $\left(n_{2}\right)$ is more sensible to $\mathrm{Sb}_{2} \mathrm{O}_{3}$ content than the two-photon absorption coefficient $\left(\alpha_{2}\right)$.

The increase in nonlinear refractive index $\left(n_{2}\right)$ is also attributed to the greater $\mathrm{Sb}-\mathrm{O}$ average bond lengths according to eq $7^{79}$

$$
n_{2}=\frac{2.5 \times 10^{-12} f_{\mathrm{L}}^{3}\left(n^{2}-1\right) d^{2} E_{\mathrm{s}}^{6}}{n\left(E_{\mathrm{s}}^{2}-E^{2}\right)^{4}}(\mathrm{esu})
$$

where $F_{\mathrm{L}}$ is the Lorentz field factor, $n$ is the refractive index, $E_{\mathrm{s}}$ is the Sellmeier gap, $E$ is the photon energy, and " $d$ " is the M$\mathrm{O}$ bond length (M: cation). In the present glasses, the three bonds are $\mathrm{Na}-\mathrm{O}, \mathrm{B}-\mathrm{O}$, and $\mathrm{Sb}-\mathrm{O}$, but the ${ }^{23} \mathrm{Na}$ MAS-NMR shows that the $\mathrm{Na}-\mathrm{O}$ bond length decreases upon incorporating $\mathrm{Sb}_{2} \mathrm{O}_{3}$. The Raman spectral measurements showed that the shorter $\mathrm{B}-\mathrm{O}$ and $\mathrm{B}-\mathrm{O}-\mathrm{B}$ bonds are replaced by $\mathrm{Sb}-\mathrm{O}, \mathrm{Sb}-\mathrm{O}-\mathrm{Sb}$, and $\mathrm{Sb}-\mathrm{O}-\mathrm{B}$ bonds upon substituting $\mathrm{Sb}_{2} \mathrm{O}_{3}$ for $\mathrm{B}_{2} \mathrm{O}_{3}$. Hence, the concentration of elongated $\mathrm{Sb}-\mathrm{O}$ bonds is greater in comparison to the shorter $\mathrm{B}-\mathrm{O}$ bonds per unit volume. Therefore, the increase in $n_{2}$ as a function of $\mathrm{Sb}_{2} \mathrm{O}_{3}$ can possibly be attributed to the elongated $\mathrm{Sb}-\mathrm{O}$ bond lengths.

Furthermore, the observed nonlinearity in NBS glasses can also be explained by considering the average bond lengths. Hashimoto et al. ${ }^{80}$ explained that the glasses with transitionmetal oxides showed the highest $\chi^{(3)}$ with the shortest average bond lengths, whereas the glasses with non-transition-metal oxides (e.g., HMOs) exhibited the greatest $\chi^{(3)}$ due to the longest average bond lengths. In glass network, the $\mathrm{Sb}-\mathrm{O}$ and $\mathrm{B}-\mathrm{O}$ bond lengths are reported in the ranges of $2.0-2.6^{50}$ and 1.37-1.48 $\AA,{ }^{81}$ respectively, and the $\mathrm{Sb}-\mathrm{O}$ bond concentrations are increasing due to the incorporation of $\mathrm{Sb}_{2} \mathrm{O}_{3}$ in the composition; hence, the average bond lengths in the present
NBS glasses are greater than $\mathrm{B}-\mathrm{O}$ bond lengths. Therefore, the enhancement in $\chi^{(3)}$ is also attributed to large average $\mathrm{Sb}-$ $\mathrm{O}$ bond lengths. The sodium NMR clearly indicates the shortening of the $\mathrm{Na}-\mathrm{O}$ bond lengths upon the substitution of $\mathrm{Sb}_{2} \mathrm{O}_{3}$ for $\mathrm{B}_{2} \mathrm{O}_{3}$ in the glass composition; hence, the influence $\mathrm{Na}-\mathrm{O}$ average bond lengths can be ignored.

On the application side, to propose the glasses for nonlinear device applications figure of merit is a distinct criterion and is given by

$$
F=\frac{2 \alpha_{2} \lambda}{n_{2}}
$$

where $F$ is the figure of merit, $\alpha_{2}$ is the two-photon absorption coefficient, $\lambda$ is the excitation wavelength, and $n_{2}$ is the nonlinear refractive index. When the condition $F<1$ is satisfied, the glasses could be used for switching applications such as passive mode locking and optical Q-switching of lasers (to produce ultrashort pulses). However, if $F>1$ is satisfied, then the glasses could be used for nonlinear limiting applications such as to protect the human eyes and optical sensors from high-fluence irradiation, etc. In the present investigation, the studied glasses possess $F>1$ and, therefore, antimony-containing NBS glasses have potential as ultrafast optical limiters.

\section{CONCLUSIONS}

In summary, the physical, optical, structural, and third-order NLO studies were performed and analyzed to understand the influence of antimony on the structure and optical properties of sodium borate glass system and also to evaluate their suitability for NLO applications. The studied glasses possess good optical transparency and high linear refractive index. The decrease in optical band gap as a function of $\mathrm{Sb}_{2} \mathrm{O}_{3}$ and the ${ }^{11} \mathrm{~B}$ MAS-NMR studies clearly evidence the enhancement of NBO content in the glasses due to the incorporation of antimony. The Raman scattering results confirmed the formation of B$\mathrm{O}-\mathrm{Sb}$ and $\mathrm{Sb}-\mathrm{O}-\mathrm{Sb}$ bands in antimony-containing glasses. ${ }^{11} \mathrm{~B}$ MAS-NMR results disclosed that the $\mathrm{N}_{4}$ is linearly increased with gradual substitution of $\mathrm{Sb}_{2} \mathrm{O}_{3}$ for $\mathrm{B}_{2} \mathrm{O}_{3}$ due to the oxidation process of $\mathrm{Sb}^{3+}$. The fs NLO measurements confirmed that the $\alpha_{2}$ and $n_{2}$ values showed an increasing trend as a function of $\mathrm{Sb}_{2} \mathrm{O}_{3}$, which is ascribed to the hyperpolarizability of $\mathrm{Sb}^{3+}$ and $\mathrm{Sb}^{5+}$ and also due to the enhanced NBO content. Furthermore, the figure of merit of all investigated antimony-containing NBS glasses revealed that they are potential materials for optical limiting applications.

\section{AUTHOR INFORMATION}

\section{Corresponding Authors}

*E-mail: eraiah@rediffmail.com (B.E).

*E-mail: jmf@ua.pt (J.M.F.F.).

*E-mail: aareddy@cgcri.res.in (A.R.A).

ORCID

K. Jayanthi: 0000-0002-5016-3575

José M. F. Ferreira: 0000-0002-7520-2809

Amarnath R. Allu: 0000-0003-0450-0929

\section{Author Contributions}

${ }^{\#}$ G.J. and A.G. contributed equally to this work.

\section{Notes}

The authors declare no competing financial interest. 


\section{ACKNOWLEDGMENTS}

G.J. is grateful to late Dr. Rajan V. Anavekar, Former Professor, Department of Physics, Bangalore University, Bangalore, India, for useful discussions and valuable suggestions. S.V.R. acknowledges DRDO, India, for financial support through ACRHEM. This work was also done within the scope of the project CICECO-Aveiro Institute of Materials, POCI-01-0145FEDER-007679 (FCT ref UID/CTM/50011/2013), financed by national funds through the FCT/MEC and when appropriate co-financed by FEDER under the PT2020. A.R.A. and K.A. gratefully acknowledge the support and encouragement of Dr. K. Muraleedharan, Director, CSIRCGCRI, and Dr. Ranjan Sen, Head, Glass Division, CSIRCGCRI.

\section{REFERENCES}

(1) Singh, S. P.; Karmakar, B. Photoluminescence Enhancement of $\mathrm{Eu}^{3+}$ by Energy Transfer from $\mathrm{Bi}^{2+}$ to $\mathrm{Eu}^{3+}$ in Bismuth Glass Nanocomposites. RSC Adv. 2011, 1, 751-754.

(2) Mancuso, E.; Bretcanu, O.; Marshall, M.; Dalgarno, K. W. Sensitivity of Novel Silicate and Borate-Based Glass Structures on in Vitro Bioactivity and Degradation Behaviour. Ceram. Int. 2017, 43, 12651-12657.

(3) Islam, M. T.; Felfel, R. M.; Neel, E. A. A.; Grant, D. M.; Ahmed, I.; Hossain, K. M. Z. Bioactive Calcium Phosphate-Based Glasses and Ceramics and Their Biomedical Applications: A Review. J. Tissue Eng. 2017, 8, No. 2041731417719170.

(4) Shanmugavelu, B.; Kumar, V. V. R. K.; Kuladeep, R.; Rao, D. R. Third Order Nonlinear Optical Properties of Bismuth Zinc Borate Glasses. J. Appl. Phys. 2013, 114, No. 243103.

(5) Almeida, J. M. P.; De Boni, L.; Hernandes, A. C.; Mendonça, C. R. Third-Order Nonlinear Spectra and Optical Limiting of Lead Oxifluoroborate Glasses. Opt. Express 2011, 19, 17220-17225.

(6) Hivrekar, M. M.; Sable, D. B.; Solunke, M. B.; Jadhav, K. M. Different Property Studies with Network Improvement of CdO Doped Alkali Borate Glass. J. Non-Cryst. Solids 2018, 491, 14-23.

(7) Chen, C.; Wu, Y.; Li, R. The Anionic Group Theory of the NonLinear Optical Effect and Its Applications in the Development of New High-Quality NLO Crystals in the Borate Series. Int. Rev. Phys. Chem. 1989, 8, 65-91.

(8) Zhang, W.; Yu, H.; Wu, H.; Halasyamani, S. P. Crystal Growth and Associated Properties of a Nonlinear Optical Crystal- $\mathrm{Ba}_{2} \mathrm{Zn}$ $\left(\mathrm{BO}_{3}\right)_{2}$. Crystals 2016, 6, No. 68.

(9) Luo, M.; Song, Y.; Liang, F.; Ye, N.; Lin, Z. $\mathrm{Pb}_{2} \mathrm{BO}_{3} \mathrm{Br}$ : A Novel Nonlinear Optical Lead Borate Bromine with a KBBF-Type Structure Exhibiting Strong Nonlinear Optical Response. Inorg. Chem. Front. 2018, 5, 916-921.

(10) Xue, D.; Betzler, K.; Hesse, H.; Lammers, D. Nonlinear Optical Properties of Borate Crystals. Solid State Commun. 2000, 114, 21-25.

(11) Rani, S.; Sanghi, S.; Ahlawat, N.; Agarwal, A. Influence of $\mathrm{Bi}_{2} \mathrm{O}_{3}$ on Thermal, Structural and Dielectric Properties of Lithium Zinc Bismuth Borate Glasses. J. Alloys Compd. 2014, 597, 110-118.

(12) El-Shishtawi, N. A.; Tawansi, A.; Gohar, I. A.; Holland, D. Some Physical Properties of Lead Borate Glasses. I. Influences of Heat Treatment and PbO Content. J. Phys. D: Appl. Phys. 1988, 21, 607.

(13) Rada, S.; Culea, E.; Neumann, M. Experimental and Theoretical Studies of the Structure of Tellurate-Borate Glasses Network. J. Mol. Model. 2010, 16, 1333-1338.

(14) Abo-Naf, S. M.; Darwish, H.; El-Desoky, M. M. Properties and Structure of Germanium-Containing Lithium Aluminoborate Glasses. J. Mater. Sci.: Mater. Electron. 2002, 13, 537-542.

(15) Yazdi, A. R.; Towler, M. The Effect of the Addition of Gallium on the Structure of Zinc Borate Glass with Controlled Gallium Ion Release. Mater. Des. 2016, 92, 1018-1027.

(16) Singh, G. P.; Singh, D. P. Effect of $\mathrm{WO}_{3}$ on Structural and Optical Properties of $\mathrm{CeO}_{2}-\mathrm{PbO}-\mathrm{B}_{2} \mathrm{O}_{3}$ glasses. Phys. B 2011, 406, 640-644.
(17) Terashima, K.; Hashimoto, T.; Uchino, T.; Kim, S.-H.; Yoko, T. Structure and Nonlinear Optical Properties of $\mathrm{Sb}_{2} \mathrm{O}_{3}-\mathrm{B}_{2} \mathrm{O}_{3}$ Binary Glasses. J. Ceram. Soc. Jpn. 1996, 104, 1008-1014.

(18) Rao, M. V.; Kumar, V. V. R. K.; Shihab, N.; Rao, D. N. Z-Scan Studies of Barium Bismuth Borate Glasses. Opt. Mater. 2018, 84, $178-183$.

(19) Rao, M. V.; Kumar, V. V. R. K.; Shihab, N. K.; Rao, D. N. Third Order Nonlinear and Optical Limiting Properties of Alkaline Bismuth Borate Glasses. Opt. Laser Technol. 2018, 107, 110-115.

(20) Munoz-Martin, D.; de La Cruz, A. R.; Fernandez-Navarro, J. M.; Domingo, C.; Solis, J.; Gonzalo, J. Structural Origin of the Nonlinear Optical Properties of Lead Niobium Germanate Film Glasses. J. Appl. Phys. 2011, 110, No. 023522.

(21) Som, T.; Karmakar, B. Structure and Properties of Low Phonon Antimony Glasses in the $\mathrm{K}_{2} \mathrm{O}-\mathrm{B}_{2} \mathrm{O}_{3}-\mathrm{Sb}_{2} \mathrm{O}_{3}-\mathrm{ZnO}$ System. J. Am. Ceram. Soc. 2009, 92, 2230-2236.

(22) Qian, Q.; Zhang, Q. Y.; Jiang, H. F.; Yang, Z. M.; Jiang, Z. H. The Spectroscopic Properties of $\mathrm{Er}^{3+}$-Doped Antimony-borate Glasses. Phys. B 2010, 405, 2220-2225.

(23) Gandhi, Y.; Purnachand, N.; Sudhakar, K. S. V.; Satyanarayana, T.; Veeraiah, N. Influence of Modifier Oxides on Some Physical Properties of Antimony Borate Glass System Doped with $\mathrm{V}_{2} \mathrm{O}_{5}$. Mater. Chem. Phys. 2010, 120, 89-97.

(24) Honma, T.; Benino, Y.; Komatsu, T.; Sato, R.; Dimitrov, V. Structural Relaxation Kinetics of Antimony Borate Glasses with Covalent Bonding Character. J. Chem. Phys. 2001, 115, 7207-7214.

(25) Nalin, M.; Messaddeq, Y.; Ribeiro, S. J. L.; Poulain, M.; Briois, V.; Brunklaus, G.; Rosenhahn, C.; Mosel, B. D.; Eckert, H. Structural Organization and Thermal Properties of the $\mathrm{Sb}_{2} \mathrm{O}_{3}-\mathrm{SbPO}_{4}$ Glass System. J. Mater. Chem. 2004, 14, 3398-3405.

(26) Holland, D.; Hannon, A. C.; Smith, M. E.; Johnson, C. E.; Thomas, M. F.; Beesley, A. M. The Role of $\mathrm{Sb}^{5+}$ in the Structure of $\mathrm{Sb}_{2} \mathrm{O}_{3}-\mathrm{B}_{2} \mathrm{O}_{3}$ Binary Glasses-an NMR and Mössbauer Spectroscopy Study. Solid State Nucl. Magn. Reson. 2004, 26, 172-179.

(27) Falcão-Filho, E. L.; de Araújo, C. B.; Bosco, C. A. C.; Maciel, G. S.; Acioli, L. H.; Nalin, M.; Messaddeq, Y. Antimony Orthophosphate Glasses with Large Nonlinear Refractive Indices, Low Two-Photon Absorption Coefficients, and Ultrafast Response. J. Appl. Phys. 2004, 97, No. 013505.

(28) Jagannath, G.; Eraiah, B.; NagaKrishnakanth, K.; Venugopal Rao, S. Linear and Nonlinear Optical Properties of Gold Nanoparticles Doped Borate Glasses. J. Non-Cryst. Solids 2018, 482, 160169.

(29) Som, T.; Karmakar, B. Structure and Properties of Low Phonon Antimony Glasses in the $\mathrm{K}_{2} \mathrm{O}-\mathrm{B}_{2} \mathrm{O}_{3}-\mathrm{Sb}_{2} \mathrm{O}_{3}-\mathrm{ZnO}$ System. J. Am. Ceram. Soc. 2009, 92, 2230-2236.

(30) Som, T.; Karmakar, B. Infrared-to-Red Upconversion Luminescence in Samarium-Doped Antimony Glasses. J. Lumin. 2008, 128, 1989-1996.

(31) Sheik-Bahae, M.; Said, A. A.; Wei, T.-H.; Hagan, D. J.; Van Stryland, E. W. Van. Sensitive Measurement of Optical Nonlinearities Using a Single Beam. IEEE J. Quantum Electron. 1990, 26, 760-769.

(32) Massiot, D.; Fayon, F.; Capron, M.; King, I.; Le Calvé, S.; Alonso, B.; Durand, J.-O.; Bujoli, B.; Gan, Z.; Hoatson, G. Modelling One- and Two-Dimensional Solid-State NMR Spectra. Magn. Reson. Chem. 2002, 40, 70-76.

(33) Subhadra, M.; Kistaiah, P. Effect of $\mathrm{Bi}_{2} \mathrm{O}_{3}$ content on Physical and Optical Properties of $15 \mathrm{Li}_{2} \mathrm{O}-15 \mathrm{~K}_{2} \mathrm{O}-\mathrm{xBi}_{2} \mathrm{O}_{3}-(65-\mathrm{x}) \mathrm{B}_{2} \mathrm{O}_{3}$ : $5 \mathrm{~V}_{2} \mathrm{O}_{5}$ glass System. Phys. B 2011, 406, 1501-1505.

(34) Saritha, D.; Markandeya, Y.; Salagram, M.; Vithal, M.; Singh, A. K.; Bhikshamaiah, G. Effect of $\mathrm{Bi}_{2} \mathrm{O}_{3}$ on Physical, Optical and Structural Studies of $\mathrm{ZnO}-\mathrm{Bi}_{2} \mathrm{O}_{3}-\mathrm{B}_{2} \mathrm{O}_{3}$ Glasses. J. Non-Cryst. Solids 2008, 354, 5573-5579.

(35) Gao, G.; Hu, L.; Fan, H.; Wang, G.; Li, K.; Feng, S.; Fan, S.; Chen, $\mathrm{H}$. Effect of $\mathrm{Bi}_{2} \mathrm{O}_{3}$ on Physical, Optical and Structural Properties of Boron Silicon Bismuthate Glasses. Opt. Mater. 2009, $32,159-163$.

(36) Rouxel, T. Elastic Properties and Short-to Medium-Range Order in Glasses. J. Am. Ceram. Soc. 2007, 90, 3019-3039. 
(37) Gaddam, A.; Fernandes, H. R.; Tulyaganov, D. U.; Pascual, M. J.; Ferreira, J. M. F. Role of Manganese on the Structure, Crystallization and Sintering of Non-Stoichiometric Lithium Disilicate Glasses. RSC Adv. 2014, 4, 13581-13592.

(38) Widanarto, W.; Sahar, M. R.; Ghoshal, S. K.; Arifin, R.; Rohani, M. S.; Hamzah, K.; Jandra, M. Natural $\mathrm{Fe}_{3} \mathrm{O}_{4}$ Nanoparticles Embedded Zinc-tellurite Glasses: Polarizability and Optical Properties. Mater. Chem. Phys. 2013, 138, 174-178.

(39) Davis, E. A.; Mott, N. F. Conduction in Non-Crystalline Systems V. Conductivity, Optical Absorption and Photoconductivity in Amorphous Semiconductors. Philos. Mag. 1970, 22, 0903-0922.

(40) Bjoern, O. M.; Larry, W. F.; David, V.; Friedrich, A. S. Curvefitting of Raman spectra of silicate glasses. Am. Mineral. 1982, 67, 686-695.

(41) Meera, B. N.; Ramakrishna, J. Raman Spectral Studies of Borate Glasses. J. Non-Cryst. Solids 1993, 159, 1.

(42) Dwivedi, B. P.; Khanna, B. N. Cation Dependence of Raman Scattering in Alkali Borate Glasses. J. Phys. Chem. Solids 1995, 56, 3949.

(43) Svenson, M. N.; Youngman, R. E.; Yue, Y.; Rzoska, S. J.; Bockowski, M.; Jensen, L. R.; Smedskjaer, M. M. Volume and Structural Relaxation in Compressed Sodium Borate Glass. Phys. Chem. Chem. Phys. 2016, 18, 29879-29891.

(44) Yadav, A. K.; Singh, P. A Review of the Structures of Oxide Glasses by Raman Spectroscopy. RSC Adv. 2015, 5, 67583-67609.

(45) Padmaja, G.; Kistaiah, P. Infrared and Raman Spectroscopic Studies on Alkali Borate Glasses: Evidence of Mixed Alkali Effect. J. Phys. Chem. A 2009, 113, 2397-2404.

(46) Kamitsos, E. I.; Karakassides, M. A.; Chryssikos, G. D. Vibrational Spectra of Magnesium-Sodium-Borate Glasses. J. Phys. Chem. 1987, 91, 1073-1079.

(47) Franco, D. F.; Sant'Ana, A. C.; De Oliveira, L. F. C.; Silva, M. A. P. The $\mathrm{Sb}_{2} \mathrm{O}_{3}$ Redox Route to Obtain Copper Nanoparticles in Glasses with Plasmonic Properties. J. Mater. Chem. C 2015, 3, 38033808.

(48) Dubois, B.; Videau, J. J.; Couzi, M.; Portier, J. Structural Approach of the $\left(\mathrm{xPbCl}_{2}-(1-\mathrm{x}) \mathrm{Sb}_{2} \mathrm{O}_{3}\right)$ Glass System. J. Non-Cryst. Solids 1986, 88, 355-365.

(49) Flower, G. L.; Baskaran, G. S.; Reddy, M. S.; Veeraiah, N. The Structural Investigations of $\mathrm{PbO}-\mathrm{P}_{2} \mathrm{O}_{5}-\mathrm{Sb}_{2} \mathrm{O}_{3}$ Glasses with $\mathrm{MoO}_{3}$ as Additive by Means of Dielectric, Spectroscopic and Magnetic Studies. Phys. B 2007, 393, 61-72.

(50) Reddy, M. S.; Krishna, G. M.; Veeraiah, N. Spectroscopic and Magnetic Studies of Manganese Ions in $\mathrm{ZnO}-\mathrm{Sb}_{2} \mathrm{O}_{3}-\mathrm{B}_{2} \mathrm{O}_{3}$ glass System. J. Phys. Chem. Solids 2006, 67, 789-795.

(51) Sen, S.; Xu, Z.; Stebbins, J. Temperature Dependent Structural Changes in Borate, Borosilicate and Boroaluminate Liquids: HighResolution ${ }^{11} \mathrm{~B},{ }^{29} \mathrm{Si}$ and ${ }^{27} \mathrm{Al}$ NMR Studies. J. Non-Cryst. Solids 1998, 226, 29-40.

(52) Frederiksen, K. F.; Januchta, K.; Mascaraque, N.; Youngman, R. E.; Bauchy, M.; Rzoska, S. J.; Bockowski, M.; Smedskjaer, M. M. Structural Compromise between High Hardness and Crack Resistance in Aluminoborate Glasses. J. Phys. Chem. B 2018, 122, 6287-6295.

(53) Kapoor, S.; Januchta, K.; Youngman, R. E.; Guo, X.; Mauro, J. C.; Bauchy, M.; Rzoska, S. J.; Bockowski, M.; Jensen, L. R.; Smedskjaer, M. M. Combining High Hardness and Crack Resistance in Mixed Network Glasses through High-Temperature Densification. Phys. Rev. Mater. 2018, 2, No. 063603.

(54) Stebbins, J. F.; Zhao, P.; Kroeker, S. Non-Bridging Oxygens in Borate Glasses: Characterization by ${ }^{11} \mathrm{~B}$ and ${ }^{17} \mathrm{O}$ MAS and 3Q MAS NMR. Solid State Nucl. Magn. Reson. 2000, 16, 9-19.

(55) Youngman, R. E.; Zwanziger, J. W. Network Modification in Potassium Borate Glasses: Structural Studies with NMR and Raman Spectroscopies. J. Phys. Chem. 1996, 100, 16720-16728.

(56) Pascuta, P.; Culea, E. Structural and Thermal Properties of Some Zinc Borate Glasses Containing Gadolinium Ions. J. Mater. Sci.: Mater. Electron. 2011, 22, 1060-1066.
(57) Youngman, R. E.; Sen, S.; Cornelius, L. K.; Ellison, A. J. G. Novel Structural Aspects of $\mathrm{Sb}_{2} \mathrm{O}_{3}-\mathrm{B}_{2} \mathrm{O}_{3}$ Glasses. Phys. Chem. Glasses 2003, 44, 69-74.

(58) Angeli, F.; Delaye, J. M.; Charpentier, T.; Petit, J. C.; Ghaleb, D.; Faucon, P. Influence of Glass Chemical Composition on the Na-O Bond Distance: A ${ }^{23} \mathrm{Na} 3 \mathrm{Q}-\mathrm{MAS}$ NMR and Molecular Dynamics Study. J. Non-Cryst. Solids 2000, 276, 132-144.

(59) Kumar, R. S. S.; Rao, S. V.; Giribabu, L.; Rao, D. N. Femtosecond and Nanosecond Nonlinear Optical Properties of Alkyl Phthalocyanines Studied Using Z-Scan Technique. Chem. Phys. Lett. 2007, 447, 274-278.

(60) Kolavekar, S. B.; Ayachit, N. H.; Jagannath, G.; NagaKrishnakanth, K.; Rao, S. V. Optical, Structural and Near-IR NLO Properties of Gold Nanoparticles Doped Sodium Zinc Borate Glasses. Opt. Mater. 2018, 83, 34-42.

(61) Manzani, D.; de Araújo, C. B.; Boudebs, G.; Messaddeq, Y.; Ribeiro, S. J. L. The Role of $\mathrm{Bi}_{2} \mathrm{O}_{3}$ on the Thermal, Structural, and Optical Properties of Tungsten-Phosphate Glasses. J. Phys. Chem. B 2013, 117, 408-414.

(62) White, W. T.; Smith, W. L.; Milam, D. Direct Measurement of the Nonlinear Refractive-Index Coefficient $\gamma$ at $355 \mathrm{~nm}$ in Fused Silica and in BK-10 Glass. Opt. Lett. 1984, 9, 10-12.

(63) Gomes, A. S. L.; Falcão Filho, E. L.; de Araújo, C. B.; Rativa, D.; de Araujo, R. E.; Sakaguchi, K.; Mezzapesa, F. P.; Carvalho, I. C. S.; Kazansky, P. G. Third-Order Nonlinear Optical Properties of Bismuth-Borate Glasses Measured by Conventional and Thermally Managed Eclipse Z Scan. J. Appl. Phys. 2007, 101, No. 033115.

(64) Zhang, Y.; Zhang, J.; Jin, Y.; Zhang, J.; Hu, G.; Lin, S.; Yuan, R.; Liang, X.; Xiang, W. Construction and Nonlinear Optical Characterization of $\mathrm{CuO}$ Quantum Dots Doped $\mathrm{Na}_{2} \mathrm{O}-\mathrm{CaO}-\mathrm{B}_{2} \mathrm{O}_{3}-\mathrm{SiO}_{2}$ bulk Glass. J. Mater. Sci.: Mater. Electron. 2017, 28, 13201-13208.

(65) Lin, T.; Yang, Q.; Si, J.; Chen, T.; Chen, F.; Wang, X.; Hou, X.; Hirao, K. Ultrafast Nonlinear Optical Properties of $\mathrm{Bi}_{2} \mathrm{O}_{3}-\mathrm{B}_{2} \mathrm{O}_{3}-\mathrm{SiO}_{2}$ oxide Glass. Opt. Commun. 2007, 275, 230-233.

(66) Sugimoto, N.; Kanbara, H.; Fujiwara, S.; Tanaka, K.; Hirao, K. Ultrafast Response of Third-Order Optical Nonlinearity in Glasses Containing $\mathrm{Bi}_{2} \mathrm{O}_{3}$. Opt. Lett. 1996, 21, 1637-1639.

(67) Yu, B. L.; Bykov, A. B.; Qiu, T.; Ho, P. P.; Alfano, R. R.; Borrelli, N. Femtosecond Optical Kerr Shutter Using Lead-bismuthgallium Oxide Glass. Opt. Commun. 2003, 215, 407-411.

(68) Stebbins, J. F.; Zhao, P.; Kroeker, S. Non-Bridging Oxygens in Borate Glasses: Characterization by ${ }^{11} \mathrm{~B}$ and ${ }^{17} \mathrm{O}$ MAS and 3QMAS NMR. Solid State Nucl. Magn. Reson. 2000, 16, 9-19.

(69) Masuda, H.; Ohta, Y.; Morinaga, K. Structure of Binary Antimony Oxide Glass. J. Jpn. Inst. Met. 1995, 59, 31-36.

(70) Som, T.; Karmakar, B. Structure and Properties of Low-Phonon Antimony Glasses and Nano Glass-Ceramics in $\mathrm{K}_{2} \mathrm{O}-\mathrm{B}_{2} \mathrm{O}_{3}-\mathrm{Sb}_{2} \mathrm{O}_{3}$ System. J. Non-Cryst. Solids 2010, 356, 987-999.

(71) Jansen, V. M. The Crystal Structure of Antimony (V) Oxide. Acta Crystallogr., Sect. B: Struct. Sci., Cryst. Eng. Mater. 1979, 35, 539542.

(72) Doweidar, H. Structural Study of Density and Refractive Index of $\mathrm{Sb}_{2} \mathrm{O}_{3}-\mathrm{B}_{2} \mathrm{O}_{3}$ Glasses. J. Non-Cryst. Solids 2015, 429, 112-117.

(73) Ok, K. M.; Gittens, A.; Zhang, L.; Halasyamani, P. S. Synthesis, Structure and Characterization of Two New Antimony Oxides $\mathrm{LaSb}_{3} \mathrm{O}_{9}$ and $\mathrm{LaSb}_{5} \mathrm{O}_{12}$ : Formation of $\mathrm{LaSb}_{5} \mathrm{O}_{12}$ from the Reaction of $\mathrm{LaSb}_{3} \mathrm{O}_{9}$ with $\mathrm{Sb}_{2} \mathrm{O}_{3}$. J. Mater. Chem. 2004, 14, 116-120.

(74) Reddy, M. S.; Raju, G. N.; Nagarjuna, G.; Veeraiah, N. Structural Influence of Aluminium, Gallium and Indium Metal Oxides by Means of Dielectric and Spectroscopic Properties of $\mathrm{CaO}-\mathrm{Sb}_{2} \mathrm{O}_{3}-$ $\mathrm{B}_{2} \mathrm{O}_{3}$ Glass System. J. Alloys Compd. 2007, 438, 41-51.

(75) Shannon, R. D. Revised Effective Ionic Radii and Systematic Studies of Interatomic Distances in Halides and Chalcogenides. Acta Crystallogr., Sect. A: Found. Adv. 1976, 32, 751-767.

(76) Nasu, H.; Sugimoto, O.; Matsuoka, J.; Kamiya, K. NonResonant-Type Third-Order Optical Non-Linearity of Alkali Silicate and Alkali Aluminosilicate Glasses - Contribution of Individual Chemical Species in the Glasses to $\chi^{(3)}$. J. Non-Cryst. Solids 1995, 182, 321-327. 
(77) Zhu, X.; Li, Q.; Ming, N.; Meng, Z. Origin of Optical Nonlinearity for $\mathrm{PbO}, \mathrm{TiO}_{2}, \mathrm{~K}_{2} \mathrm{O}$, and $\mathrm{SiO}_{2}$ Optical Glasses. Appl. Phys. Lett. 1997, 71, 867-869.

(78) Karthikeyan, B.; Sandeep, C. S. S.; Cha, J.; Takebe, H.; Philip, R.; Mohan, S. Optical Properties and Ultrafast Optical Nonlinearity of Bismuthate Glasses Doped Sodium Borate and Optical Properties and Ultrafast Optical Nonlinearity of $\mathrm{Yb}^{3+}$ Doped Sodium Borate and Bismuthate Glasses. J. Appl. Phys. 2008, 103, No. 103509.

(79) Kim, S.-H.; Yoko, T. Nonlinear Optical Properties of $\mathrm{TeO}_{2}$ Based Glasses: $\mathrm{MOx}_{-} \mathrm{TeO}_{2}(\mathrm{M}=\mathrm{Sc}, \mathrm{Ti}, \mathrm{V}, \mathrm{Nb}, \mathrm{Mo}, \mathrm{Ta}$, and $\mathrm{W})$ Binary Glasses. J. Am. Ceram. Soc. 1995, 78, 1061-1065.

(80) Hashimoto, T.; Yoko, T. Third-Order Nonlinear Optical Properties of Sol-gel-Derived $\mathrm{V}_{2} \mathrm{O}_{5}, \mathrm{Nb}_{2} \mathrm{O}_{5}$, and $\mathrm{Ta}_{2} \mathrm{O}_{5}$ Thin Films. Appl. Opt. 1995, 34, 2941-2948.

(81) Mozzi, R. L.; Warren, B. E. The Structure of Vitreous Boron Oxide. J. Appl. Crystallogr. 1970, 3, 251-257. 